\title{
Demonstration of Free Radical Generation in the "Stunned" Myocardium in the Conscious Dog and Identification of Major Differences between Conscious and Open-chest Dogs
}

\author{
Xiao-Ying Li, Paul B. McCay, ${ }^{\star}$ Marcel Zughaib, Mohamed O. Jeroudi, J. Fernando Triana, and Roberto Bolli \\ With the technical assistance of Gemma Wallis* \\ Experimental Animal Laboratory, Section of Cardiology, Department of Medicine, Baylor College of Medicine, Houston, Texas 77030; \\ and *Molecular Toxicology Research Group, Oklahoma Medical Research Foundation, Oklahoma City, Oklahoma 73104
}

\section{Abstract}

Conscious dogs undergoing a 15-min coronary occlusion were given $\alpha$-phenyl $N$-tert-butyl nitrone (PBN) and the local coronary venous plasma was analyzed by electron paramagnetic resonance spectroscopy. A prolonged myocardial release of PBN radical adducts was observed, which exhibited a burst in the initial minutes of reflow (peaking at $3 \mathrm{~min}$ ) and then abated but continued for 1-3 h after reperfusion. Computer simulation revealed the presence of at least two $\mathrm{PBN}$ adducts $\left(\mathrm{a}_{\mathrm{N}}=15.2 \mathrm{G}\right.$ and $a_{\beta}{ }^{H}=6.0 \mathrm{G} ; a_{N}=14.6 \mathrm{G}$ and $\left.a_{\beta}{ }^{H}=3.0 \mathrm{G}\right)$, both consistent with the trapping of secondary carbon-centered radicals. No appreciable PBN adduct production was observed when collateral flow exceeded $30-40 \%$ of nonischemic flow, indicating that a flow reduction of at least $60 \%$ is necessary to trigger free radical reactions. There was a direct relationship between the magnitude of PBN adduct production and the severity of contractile dysfunction $(r=0.77)$, suggesting that the radicals generated upon reperfusion play a causal role in the subsequent stunning. The total release of $\mathrm{PBN}$ adducts after $3 \mathrm{~h}$ of reperfusion following a 15-min coronary occlusion was found to be approximately five times greater in open-chest compared with conscious dogs; at the same time, the recovery of wall thickening was markedly less in open-chest dogs. This study represents the first application of spin trapping to a conscious animal model of myocardial ischemia. The results demonstrate $(a)$ that free radicals are generated in the stunned myocardium in the absence of the artificial or abnormal conditions associated with previously used models ( isolated hearts, open-chest preparations), and (b) that both the severity of postischemic dysfunction and the magnitude of the attendant free radical production are greatly exaggerated in the open-chest dog, implying that previous conclusions derived from this model may not be applicable to conscious animals or to humans. This investigation also provides a method to measure free radicals in awake animals. (J. Clin. Invest. 1993. 92:1025-1041.) Key words: electron paramagnetic resonance spectroscopy $\bullet$ oxygen radicals $\bullet \alpha$-phenyl $N$-tert-butyl nitrone $\bullet$ reperfusion $\bullet$ spin trapping

Address reprint requests to Dr. Roberto Bolli, Section of Cardiology, Baylor College of Medicine, 6535 Fannin, MS-F905, Houston, TX 77030.

Received for publication 19 June 1992 and in revised form 15 March 1993.

J. Clin. Invest.

(c) The American Society for Clinical Investigation, Inc. 0021-9738/93/08/1025/17 \$2.00

Volume 92, August 1993, 1025-1041

\section{Introduction}

Recent studies using spin trapping techniques (1-7) support the hypothesis that oxygen-derived free radicals contribute to the pathogenesis of postischemic myocardial dysfunction (myocardial "stunning" [8]). These studies have shown that free radicals are generated in various animal models of stunned myocardium $(1,2,7)$, and that the generation of the radicals is inhibited by the same antioxidants that attenuate postischemic dysfunction (3-7). The validity of these concepts, however, is limited by the fact that they are predicated exclusively on results obtained in anesthetized, open-chest preparations (1-7). To our knowledge, generation of free radicals in postischemic myocardium in conscious animals has never been demonstrated. Several investigators (9-20) have pointed out that observations in open-chest models are confounded by the effects of anesthesia, surgical trauma, abnormal hemodynamic conditions, excessive levels of circulating catecholamines, and other factors. Certain conclusions derived from open-chest preparations have subsequently been found not to be applicable to conscious animals $(9,10,15,17,18,20)$. We have recently observed (21) that the severity of myocardial stunning after a 15 -min coronary occlusion is greatly exaggerated in the barbiturate-anesthetized open-chest dog, i.e., approximately half of the postischemic depression of contractility observed in this model is not present in the awake dog. The time course of recovery of contractile function is also quite different in the two models. In open-chest dogs, recovery of function ceases at $1 \mathrm{~h}$ of reperfusion and no further improvement takes place between 1 and $4 \mathrm{~h}$ of reflow (21); in contrast, in the conscious dog recovery continues unabated throughout the first $6 \mathrm{~h}$ of reperfusion and beyond until complete normalization is achieved (21).

The fact that myocardial stunning is distorted to a major extent by the anesthetized preparation raises the possibility that generation of free radicals could also be distorted to a major extent, or perhaps even artifactually caused, by the open-chest model. Conceivably, radical reactions caused by such factors as tissue trauma ( with consequent mitochondrial damage and/or release of catalytic iron), high concentrations of catecholamines (with attendant autoxidative or oxidative reactions), or systemic neutrophil activation (with consequent extracellular production of activated oxygen) may be completely absent in conscious animals. If these reactions occur at a significant rate and cause tissue damage, the results obtained in open-chest animals may not be applicable to awake animals or to humans.

In view of these considerations, the lack of data in conscious animal preparations represents a major limitation of the free radical measurements performed in vivo thus far (1- 
7). If current concepts regarding the pathogenetic role of oxyradicals in stunning are to be extrapolated to humans and used as a basis for developing clinical therapies, evidence must be provided that such concepts are valid in the absence of the abnormal conditions associated with open-chest animals. In addition, since open-chest models are widely used whereas conscious models are rarely used, it is important to ascertain whether the free radical reactions occurring after reperfusion differ in the two models and, if so, how large such differences are (i.e., to what extent results obtained in acute preparations can be applied to conscious preparations).

The present study was undertaken to address these issues. Open-chest and conscious dogs were subjected to the same duration of ischemia (a 15-min coronary occlusion) and free radical production was assessed using the same techniques (administration of the spin trap $\alpha$-phenyl $N$-tert-butyl nitrone [PBN] ${ }^{1}$ and electron paramagnetic resonance [EPR] spectroscopy). The primary goals were to determine: $(a)$ whether free radicals are generated in the stunned myocardium in the conscious, unsedated dog, and $(b)$ whether radical generation is significantly affected by the conditions associated with the barbiturate-anesthetized open-chest dog model. Additional objectives were: $(c)$ to define the relation between severity of ischemia, severity of postischemic dysfunction, and intensity of free radical formation, and $(d)$ to develop a method that enables measurement of free radical formation in conscious animals.

\section{Methods}

A total of 108 dogs ( 76 conscious and 32 open-chest) were used for this study. The experimental preparations and techniques (both in conscious and in open-chest dogs) have been previously described in detail $(1,3-5,21-28)$.

\section{Part I. Studies in conscious dogs}

Experimental preparation. Healthy mongrel dogs of either sex (20-28 $\mathrm{kg}$ ) were instrumented as previously described (21, 25-27). In addition, a no. 8F Sones catheter was introduced from the right atrium into the anterior interventricular vein; the tip of the catheter was positioned at the same level as the coronary occluder ( mid left anterior descending coronary artery [LAD]), so as to minimize any contamination of blood samples with venous effluent from other vascular beds $(1,3-5)$ (the position of the catheter was confirmed in all dogs at postmortem examination). Dogs were allowed to recover for a minimum of $7 \mathrm{~d}$ after surgery and were trained for at least $3 \mathrm{~d}$ until they became acclimatized to the laboratory environment. Throughout the study, they were studied in the awake, unsedated state while standing quietly in a sling.

Pilot studies demonstrated that catheters placed in the anterior interventricular vein, even when filled with heparin and flushed daily, became invariably occluded by clots within $48 \mathrm{~h}$. To prevent this problem, the coronary venous catheter was infused with a solution of heparin in normal saline $(30 \mathrm{U} / \mathrm{kg} / \mathrm{h}$ of heparin; $1.7 \mathrm{ml} / \mathrm{h})$ by means of a portable infusion pump (Auto Syringe, model AS2F, Travenol Laboratories) attached to the dog jacket. The pump was refilled daily, so that heparin was infused continuously from instrumentation until sacrifice.

Experimental protocol. The LAD was occluded for $15 \mathrm{~min}$ and then reperfused. Regional myocardial blood flow was determined by the radioactive microsphere technique (25) before and 8-10 min after

1. Abbreviations used in this paper: EPR, electron paramagnetic resonance; $L A D$, left anterior descending coronary artery; $L V$, left ventricular; PBN, $\alpha$-phenyl- $N$-tert-butyl nitrone.
LAD occlusion. Regional myocardial function was assessed as systolic thickening fraction (i.e., systolic wall thickening/end-diastolic thickness $\times 100$ ) using the epicardial Doppler probe, as previously described (1, 3-5, 21-27). At the end of the study, the size of the occluded/reperfused vascular bed was determined by a postmortem dual-perfusion technique (22). Tetrazolium staining confirmed the absence of infarction in all animals.

The spin trapping agent PBN (Sigma Chemical Co., St. Louis, MO) was dissolved in normal saline, filtered through a $0.22-\mu \mathrm{m}$ filter (Millipore Corp., Bedford, MA), and infused intravenously (through the jugular line) over $30 \mathrm{~min}$ at a rate of $1.67 \mathrm{mg} / \mathrm{kg}$ per min (total dose of PBN $50 \mathrm{mg} / \mathrm{kg}$; total volume of solution infused $100 \mathrm{ml}$ ). Dogs were assigned to three groups. In group I (radical trapping in stunned myocardium), the LAD was occluded for $15 \mathrm{~min}$ and PBN was infused as described above starting $5 \mathrm{~min}$ before LAD occlusion and ending 10 min after reperfusion. In group II (controls for EPR signals), PBN was infused for $30 \mathrm{~min}$ at the same rate as in group I, but no coronary occlusion was performed. Group III (controls for recovery of function) underwent the same protocol as group I except that PBN was not given.

$E P R$ analysis. Blood samples $(6 \mathrm{ml})$ were drawn over a 60 -s period from the aorta or from the anterior interventricular vein and immediately centrifuged. The plasma specimens were frozen at $-70^{\circ} \mathrm{C}$ for subsequent analysis by EPR spectroscopy. The techniques used to detect spin adducts of reactive free radicals and to quantify the myocardial release of these species into the coronary venous effluent blood have been described in detail $(1,29)$. In this study, the intensity of the EPR signals was assessed by measuring (in millimeters) the cumulative height of the first three lines of the spectrum, adjusted for the gain of the scan (see Figs. 1 and 2). The first triplet was selected for these measurements because it was not affected by the (inconsistent) presence of $\alpha$-tocopheroxyl radicals (see Results). In the present study, the arterial samples exhibited either weak EPR signals or no signals. When a weak EPR signal was observed, the net signal intensity in the venous plasma was calculated as the difference between the signal intensity in the venous plasma sample and the signal intensity in the simultaneous arterial plasma sample. The myocardial release of spin adducts was calculated (in arbitrary units [U] per minute) by multiplying the net signal intensity in the venous plasma (units per milliliter) by the simultaneous LAD blood flow (milliliters per minute); this quantity was normalized to the size of the occluded/reperfused bed (grams). Thus, the myocardial release of spin adducts at a specific time point was expressed in arbitrary units per minute per gram of reperfused myocardium (1, 3-5); the total cumulative myocardial production of PBN adducts over a given interval of time was calculated by integrating the measurements obtained at individual time points $(1,3-5)$.

Measurement of $P B N$ plasma levels. At selected time points $(2,5$, and $10 \mathrm{~min}$ and 2,4 , and $6 \mathrm{~h}$ of reperfusion), the concentration of PBN in the arterial plasma samples obtained in group I was determined as follows. To $50 \mu \mathrm{l}$ of plasma was added $10 \mu \mathrm{l}$ of a $10 \%$ solution of SDS. To this mixture was added $0.94 \mathrm{ml}$ of absolute ethanol. The samples were then mixed by vortexing and then centrifuged for 15 min to sediment precipitated proteins. The concentration of PBN was then determined by direct ultraviolet absorbance at $295 \mathrm{~nm}$. The readings obtained were corrected for any absorption in plasma samples from the same dog that did not contain PBN. Since the extinction coefficient for PBN in ethanol is 16,700 , this procedure is relatively sensitive; it was found to yield reproducible values when known amounts of PBN were added to dog plasma.

Pharmacokinetics of PBN. To determine the pharmacokinetics of PBN, a separate group of conscious dogs $(n=6)$, instrumented as in group I, was given an i.v. infusion of PBN as in group I. The concentration of PBN in the arterial plasma was measured 5, 15, 20, and $25 \mathrm{~min}$ into the infusion of PBN, at the end of the infusion, and 10, 20, and 30 min, and $1,1.5,2,3,4,5,6,8$, and $10 \mathrm{~h}$ after the infusion. The area under the curve was calculated by the trapezoidal rule and extrapolated to infinity. The pharmacokinetic parameters were calculated according to standard equations. The terminal elimination half-life was determined by linear regression using at least three concentrations. 
Observed Spectra
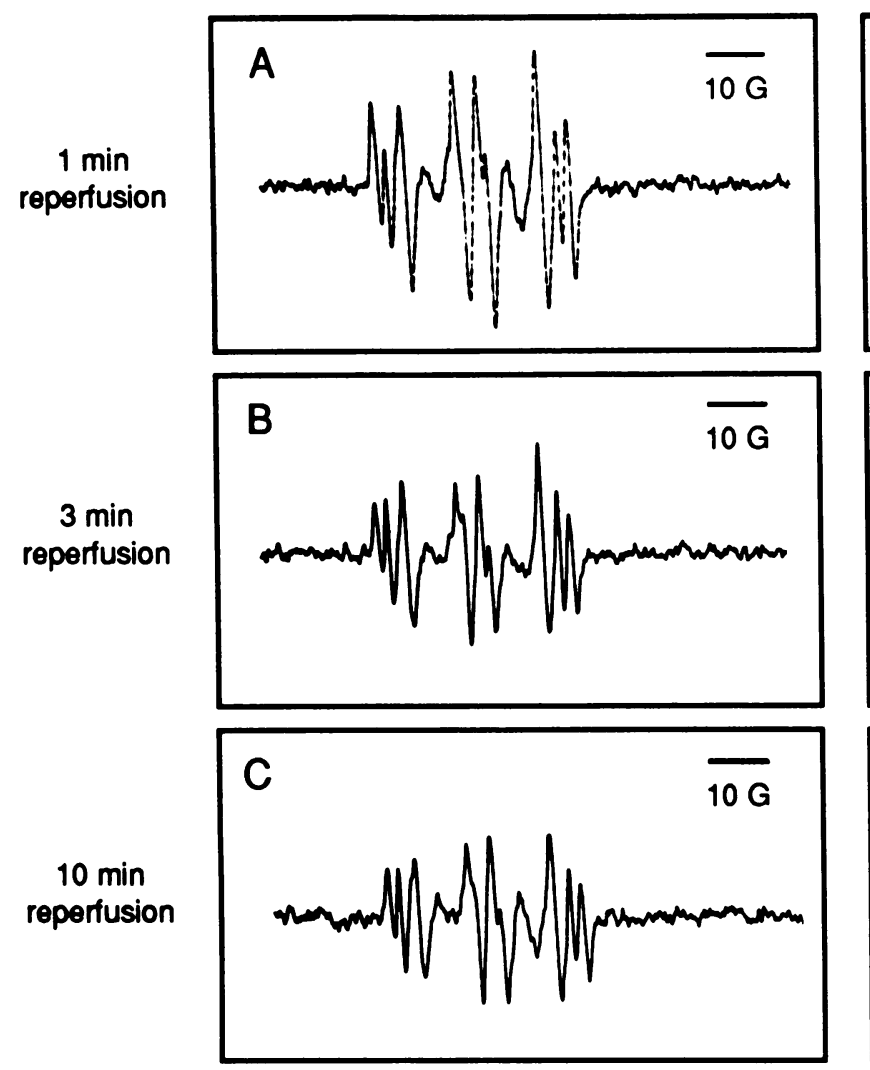

Simulated Spectra
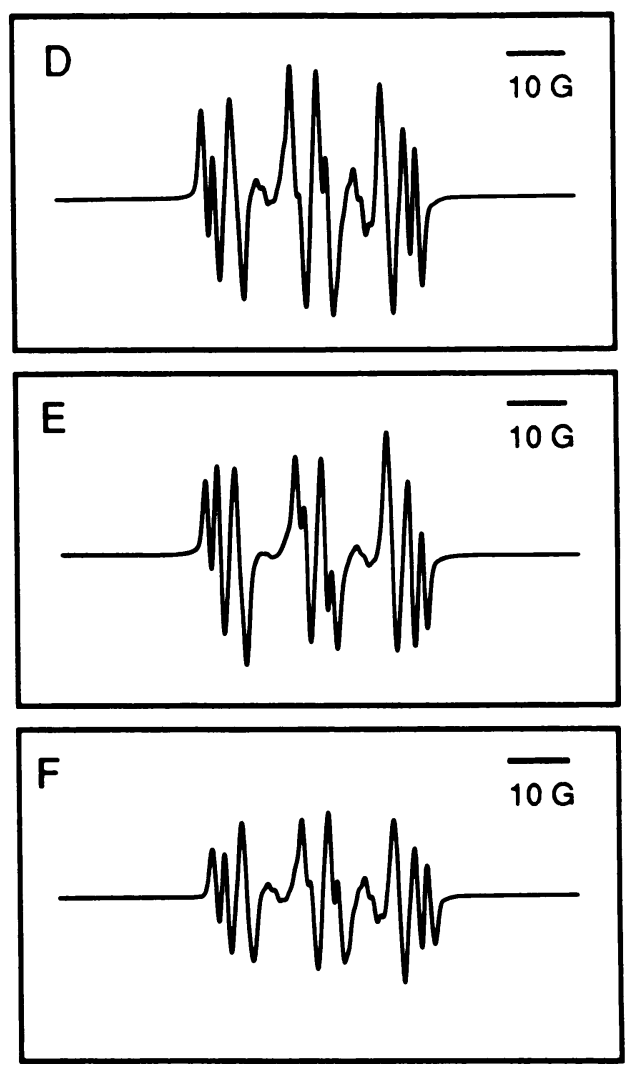

Figure 1. Left panel: EPR spectra of PBN radical adducts observed in coronary venous blood draining from the reperfused region of a dog in group I. The horizontal bars above each spectrum indicate $10 \mathrm{G}$. Shown in this figure are signals from plasma samples obtained $(A) 1 \mathrm{~min}$ after reperfusion (gain, $1.0 \times 10^{6}$ ), $(B) 3 \mathrm{~min}$ after reperfusion (gain, $1.0 \times 10^{6}$ ), and $(C) 10$ min after reperfusion $\left(\right.$ gain, $1.0 \times 10^{6}$ ). Right panel: $D, E$, and $F$ are computer-generated simulations of spectra $A, B$, and $C$, respectively. The coupling constants for the various components of these simulated spectra (component radical 1, component radical 2, and $\alpha$-tocopheroxyl radical) are given in Fig. 4 . The simulated spectra were generated by combining the component radical 1 , the component radical 2 , and the $\alpha$-tocopheroxyl radical, respectively, at the following area ratios: $(D)$ 1.00:1.00:2.17; $(E)$ 1.00:4.43:1.71; $(F)$ 1.00:1.50:3.06. The different proportions of the various component radicals in spectra $A, B$, and $C$ result in some differences in peak intensities between these samples. The spectrometer settings were as follows: microwave power, 20.0 $\mathrm{mW}$; modulation amplitude, $0.975 \mathrm{G}$; time constant, $1.31 \mathrm{~s}$; scan range, $100 \mathrm{G}$; and scan time, $356 \mathrm{~s}$. All spectra were recorded at room temperature $\left(25^{\circ} \mathrm{C}\right)$.

Measurement of $\alpha$-tocopherol. A separate group of six conscious dogs was instrumented as in group I but no coronary occlusion was performed. Arterial blood and myocardial samples for measurement of $\alpha$-tocopherol were obtained 8-10 d after surgery, i.e., after an interval equivalent to the interval between instrumentation and LAD occlusion in group I. To avoid any variation related to feeding, the samples were obtained in the morning, i.e., at a time corresponding to the time of coronary occlusion in group I. $6 \mathrm{ml}$ of arterial blood was drawn in heparinized syringes and centrifuged. The dogs were then killed, the heart was perfused with normal saline for $2 \mathrm{~min}$ to remove the blood, and a transmural block of left ventricular (LV) tissue $(\sim 1 \mathrm{~g})$ was obtained immediately thereafter. Plasma and tissue samples were immediately frozen in liquid nitrogen. The concentration of $\alpha$-tocopherol was determined by high performance liquid chromatography (30).

\section{Part II. Studies in anesthetized dogs}

Mongrel dogs of either sex (16-24 kg) were anesthetized with sodium pentobarbital $(35 \mathrm{mg} / \mathrm{kg}$ i.v.) and instrumented as previously described $(1,3-5,21-24,28)$. A no. $8 \mathrm{~F}$ Sones catheter was introduced into the coronary sinus and advanced into the anterior interventricular vein; as in the conscious dogs, the tip of the catheter was positioned at the level of the coronary snare (mid LAD). As detailed previously ( 1 , 22 ), particular care was taken to ensure that hematocrit, body tempera- ture, arterial $\mathrm{pH}$ and $\mathrm{PO}_{2}$, and plasma potassium concentration were within normal limits for the entire duration of the protocol.

The essential features of the experimental protocol and the techniques used were identical to those described above for the conscious dogs. In short, the LAD was occluded for $15 \mathrm{~min}$ and then reperfused. PBN was administered exactly as in group I and the production of PBN adducts and the plasma levels of PBN were assessed with the same procedures used in group I. Tetrazolium staining confirmed the absence of irreversible damage in all dogs. To determine the pharmacokinetics of PBN, a separate group of open-chest dogs $(n=7)$ was given $\mathrm{PBN}$ as in group I. The arterial plasma levels of PBN were measured 5, $10,15,20$, and $25 \mathrm{~min}$ into the infusion of PBN, at the end of the infusion, and 10,20 , and $30 \mathrm{~min}$, and $1,1.5,2,3$, and $4 \mathrm{~h}$ after the infusion. In another separate group of open-chest dogs $(n=10)$, which did not undergo coronary artery occlusion and were killed immediately after anesthesia, the concentration of $\alpha$-tocopherol in the arterial plasma and in the myocardium was determined as described above for conscious dogs.

Statistical analysis. All values are reported as mean \pm SEM. The unpaired Student's $t$ test was used to compare means between two groups of dogs, whereas the paired $t$ test was used to analyze intragroup variation; the resulting $P$ values were adjusted by the Bonferroni correction for multiple comparisons (31). Comparisons of hemodynamic 


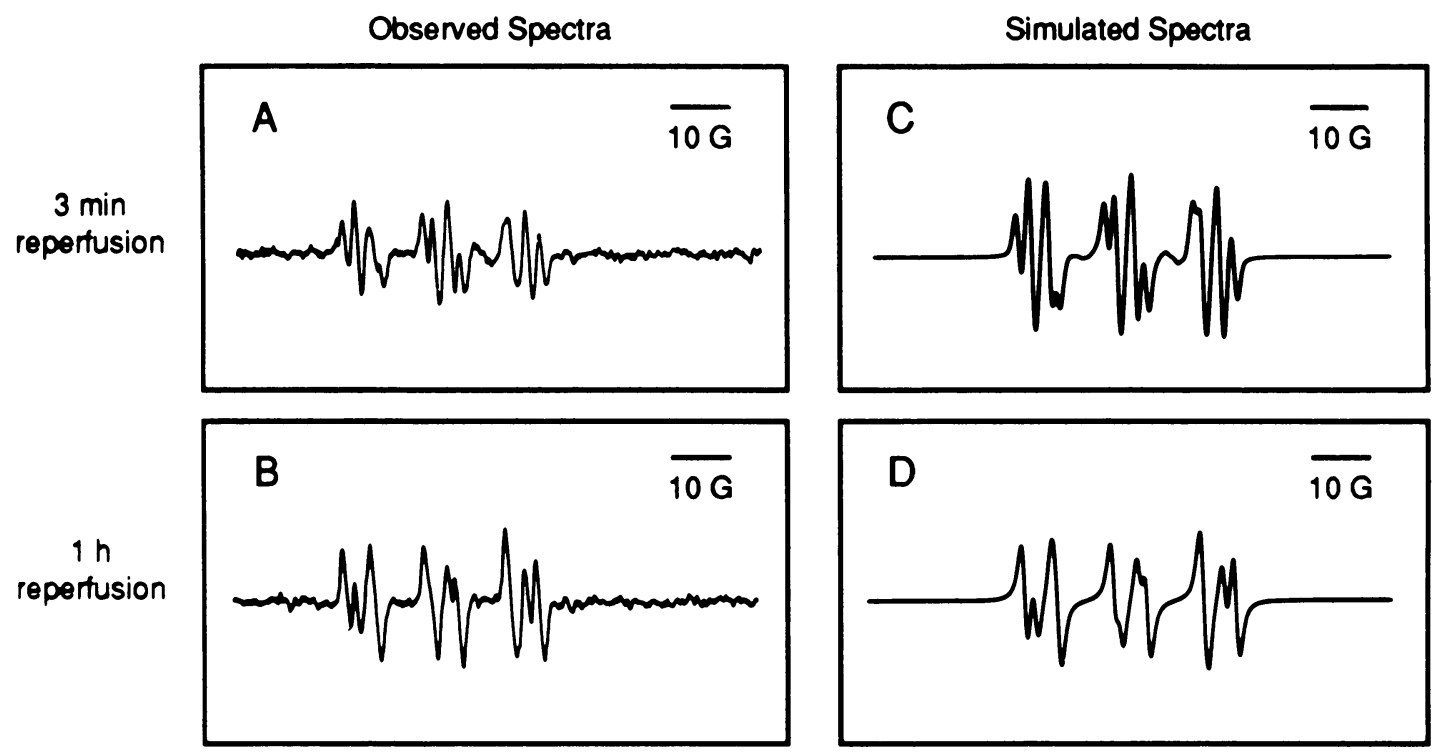

Figure 2. Left panel: EPR spectra of PBN radical adducts observed in coronary venous blood draining from the reperfused region of a dog in group I. The horizontal bars above each spectrum indicate $10 \mathrm{G}$. Shown in this figure are signals from plasma samples obtained $(A) 3 \mathrm{~min}$ after reperfusion (gain, $1.0 \times 10^{6}$ ) and $(B) 1 \mathrm{~h}$ after reperfusion (gain, $1.0 \times 10^{6}$ ). Right panel: $C$ and $D$ are computer-generated simulations of spectra $A$ and $B$, respectively. The coupling constants for the various components of these simulated spectra (component radical 1, component radical 2 , and $\alpha$-tocopheroxyl radical) are given in Fig. 4 . The simulated spectra were generated by combining the component radical 1 , the component radical 2 , and the $\alpha$-tocopheroxyl radical, respectively, at the following area ratios: $(C)$ 1.00:3.81:1.44; $(D)$ 1.00:0.30:0. The different proportions of the various component radicals in spectra $A$ and $B$ result in some differences in peak intensities between these samples. The spectrometer settings were as follows: microwave power, $20.0 \mathrm{~mW}$; modulation amplitude, $0.975 \mathrm{G}$; time constant, $1.31 \mathrm{~s}$; scan range, $100 \mathrm{G}$; and scan time, $356 \mathrm{~s}$. All spectra were recorded at room temperature $\left(25^{\circ} \mathrm{C}\right)$.

variables and wall thickening between two groups at several time points were made by repeated measures analysis of variance. The relationships between dependent and independent variables were analyzed using linear regression analysis with the least-squares method or, if the relationship was curvilinear, using computer-generated exponential regression equations $(21,25)$. All regression analyses were performed with the SAS software system (32).

\section{Results}

\section{Part I. Demonstration of free radical production in conscious dogs}

Exclusions. Of the 64 dogs instrumented for the studies of free radical production and wall thickening, 37 (58\%) were excluded for the following reasons: technical problems during instrumentation ( $7 \mathrm{dogs})$, postoperative death ( $8 \mathrm{dogs})$, spontaneous occlusion of the LAD during convalescence ( $3 \mathrm{dogs}$ ), streptokinase-induced hemothorax ( 2 dogs), inability to draw blood from the coronary venous catheter ( 9 dogs), lack of dyskinesis during ischemia ( 2 dogs), ventricular fibrillation during LAD occlusion ( $1 \mathrm{dog}$ ) or upon reperfusion ( $4 \mathrm{dogs}$ ), and spontaneous LAD occlusion after reperfusion $(1 \mathrm{dog})$. The proportion of intraoperative and postoperative exclusions was particularly high in groups I and II ( $68 \%$ and $67 \%$, respectively, of the dogs instrumented), reflecting the technical difficulties associated with placing a catheter in the mid anterior interventricular vein and keeping it patent for 1-2 wk. We suspect that some of the postoperative deaths in groups I and II resulted from bleeding induced by the administration of heparin through the coronary venous catheter (three dogs were found to have $>400 \mathrm{ml}$ of bloody fluid in the chest cavity). Even with a continuous infusion of heparin, in some cases the catheter became totally occluded by a thrombus 3-5 d after instrumentation; in other cases, the catheter was not completely occluded (i.e., fluids could be injected), but withdrawal of blood samples was not possible (perhaps because of a valve thrombus in the catheter tip or in the vein). Injection of streptokinase (either through the catheter or intravenously) did not reestablish the patency of the catheter in any dog, and actually caused a fatal hemothorax in at least two animals, as indicated above.

The final analysis included 10 dogs in group I, 7 dogs in group II, and 13 dogs in group III. Of the 10 dogs that were included in group I, only 8 could be used for the studies of PBN adduct production because in 2 dogs the coronary venous catheter became malfunctional during coronary occlusion (i.e., after reperfusion blood samples could not be drawn as scheduled). Furthermore, in 2 other dogs the wall thickening signals were of inadequate quality, so that only 8 of the 10 animals could be used for the studies of recovery of function. Thus, the data on production of PBN adducts (Figs. 1-5) are based on the eight dogs in which the venous samples could be taken as scheduled; the data on systemic hemodynamics (Table I), wall thickening (Table I), regional myocardial blood flow (Table II), and occluded bed size are based on the eight dogs in which adequate wall thickening signals could be obtained; the correlation between production of PBN adducts and deficit of function (Fig. 6) is based on the six dogs in which both of these variables could be measured (i.e., the venous samples could be drawn as scheduled and the wall thickening signals were of satisfactory quality).

Of the seven dogs that were included in group II, four were used only for the studies in this group and three were used also 

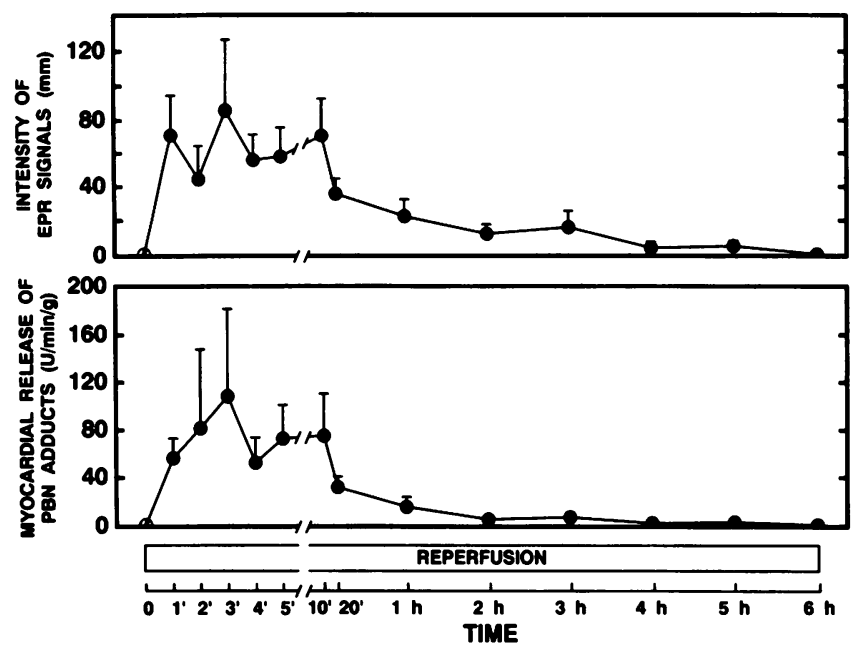

Figure 3. Upper panel: Net intensity of EPR signals in the coronary venous effluent blood in group I. Lower panel: Time course of myocardial release of $\mathrm{PBN}$ adducts in group I. Data are mean \pm SEM. See text for explanation of units used.

for the studies in group I. In these latter three dogs, PBN was infused during LAD occlusion (protocol for group I); after at least $48 \mathrm{~h}$ of reperfusion, PBN was infused again without LAD occlusion (protocol for group II). Thus, the final analysis included seven dogs used only for group I, four used only for group II, and three used for both. It should be noted that in the three dogs used for both groups I and II, the protocol for group I always preceded the protocol for group II.
Two separate groups of six dogs each were used for the assessment of PBN pharmacokinetics and for the measurement of $\alpha$-tocopherol; none of these dogs was excluded.

Arterial blood gases, hematocrit, and temperature. On the day of coronary occlusion, arterial $\mathrm{pH}, \mathrm{PO}_{2}$, and hematocrit and rectal temperature were within physiological limits in every animal. In groups I, II, and III, respectively, the values were: $\mathrm{pH}, 7.46 \pm 0.01,7.42 \pm 0.01$, and $7.44 \pm 0.01 ; \mathrm{PO}_{2}, 84 \pm 4$, $92 \pm 4$, and $85 \pm 2 \mathrm{mmHg}$; hematocrit, $41 \pm 2 \%, 47 \pm 3 \%$, and $43 \pm 2 \%$; temperature, $39.1 \pm 0.2,38.4 \pm 0.4$, and $39.0 \pm 0.2^{\circ} \mathrm{C}$ (the range of normal rectal temperatures in dogs is 37.8 $\left.39.9^{\circ} \mathrm{C}[33]\right)$

Hemodynamic variables. In group II, the infusion of PBN did not produce any significant effect on systemic hemodynamics, coronary blood flow, or LV wall thickening. For example, the following measurements were obtained at baseline, 15 min into the infusion of PBN and 10 min after the end of the PBN infusion, respectively: heart rate, $126 \pm 4,134 \pm 11$, and $129 \pm 7$ beats / min; mean arterial pressure, $109 \pm 6,101 \pm 6$, and $105 \pm 5 \mathrm{mmHg}$; LAD flow (normalized to the weight of the occluded/reperfused bed), $1.40 \pm 0.36,1.28 \pm 0.38$, and $1.48 \pm 0.40 \mathrm{ml} / \mathrm{min} / \mathrm{g}$; peak positive $\mathrm{LV} \mathrm{d} P / \mathrm{d} t, 3,739 \pm 1,118$, $3,326 \pm 994$, and $3,704 \pm 1,134 \mathrm{mmHg} / \mathrm{s}$; peak negative $L V \mathrm{~d} P$ / $\mathrm{d} t, 3,223 \pm 546,3,189 \pm 655$, and $3,203 \pm 636 \mathrm{mmHg} / \mathrm{s}$; thickening fraction in the anterior wall, $21.7 \pm 4.1 \%, 19.9 \pm 3.3 \%$, and $20.8 \pm 2.1 \%$; thickening fraction in the posterior wall, $19.8 \pm 1.5 \%, 21.0 \pm 1.2 \%$, and $21.1 \pm 0.9 \%$. These results indicate that, although high doses of PBN can be toxic (34), systemic administration of PBN at the dose used in this study is well tolerated in the awake animal, with no apparent cardiac toxicity or adverse hemodynamic effects.
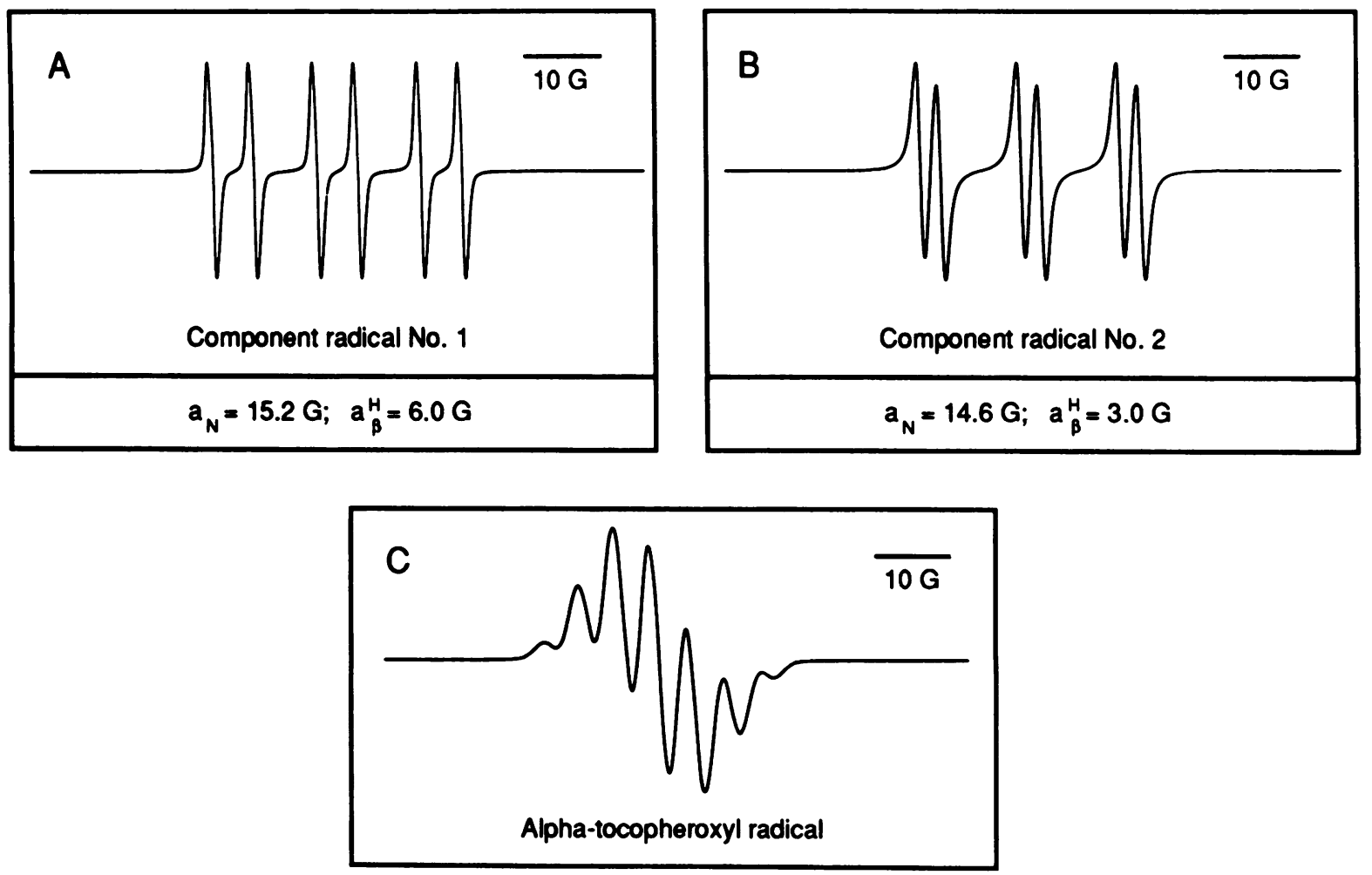

Figure 4. Computer-generated EPR spectra of component radicals believed to form the spectra shown in Figs. 1 and 2. $(A)$ Component radical 1 , with coupling constants $\mathrm{a}_{\mathrm{N}}=15.2 \mathrm{G}, \mathrm{a}_{\beta}{ }^{\mathrm{H}}=6.0 \mathrm{G} ;(B)$ component radical 2 , with coupling constants $\mathrm{a}_{\mathrm{N}}=14.6 \mathrm{G}, \mathrm{a}_{\beta}{ }^{\mathrm{H}}=3.0 \mathrm{G} ;(C)$ component radical 3, which is the $\alpha$-tocopheroxyl radical. 


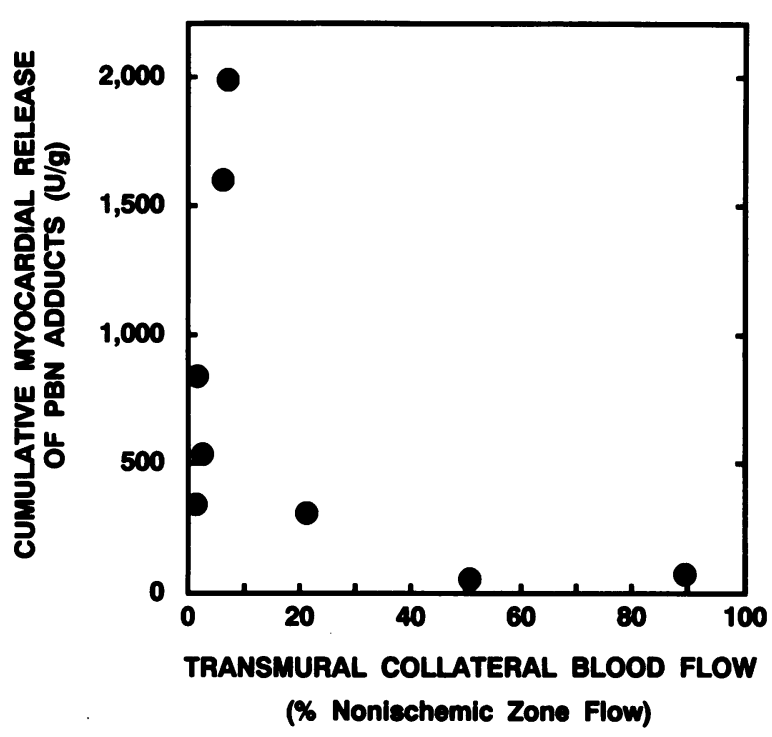

Figure 5. Relationship between mean transmural collateral blood flow to the ischemic region during coronary occlusion (horizontal axis) and total cumulative myocardial release of PBN adducts during the first $10 \mathrm{~min}$ of reperfusion (vertical axis) in group I. Collateral flow is expressed as a percentage of simultaneous nonischemic zone flow; adduct release is expressed in arbitrary units per gram of myocardium (see text for explanation of units). When all eight dogs were considered, an inverse relationship was noted, which was described best by an exponential regression equation: $Y=1047.4 e^{-0.0245 X}(r=0.67)$, where $X$ is mean transmural flow during coronary occlusion (expressed as a percentage of simultaneous nonischemic zone flow) and $Y$ is the cumulative myocardial release of PBN adducts during the first $10 \mathrm{~min}$ of reperfusion. However, the distribution of the data can be more appropriately described as a "threshold phenomenon": little or no PBN adduct production was observed when collateral flow was $>30-40 \%$ of nonischemic flow, suggesting that a severe ischemic insult (i.e., a flow reduction of at least $60 \%$ ) is necessary to trigger free radical reactions; below this threshold value, PBN adduct production did not correlate with collateral flow, suggesting that other factors in addition to collateral perfusion influence the formation of free radicals.

The hemodynamic variables in the two groups that underwent LAD occlusion (groups I and III) are summarized in Table I. Dogs in group I had faster heart rate and lower arterial pressure than dogs in group III, but since these differences were present at baseline (before PBN infusion), they cannot be ascribed to PBN. There were no significant differences between the two groups with respect to left atrial pressure, LAD flow, or $\mathrm{LV} \mathrm{d} P / \mathrm{d} t$.

Myocardial production of $P B N$ adducts. Figs. 1 and 2 show representative examples of the EPR signals observed in group I, and Fig. 3 summarizes the time course of release of PBN adducts from the ischemic/reperfused region in this group. EPR signals characteristic of radical adducts of PBN appeared in the coronary venous effluent immediately after reperfusion (Figs. 1-3). The release of PBN adducts exhibited an initial burst peaking $3 \mathrm{~min}$ after reperfusion, and then declined markedly. After the first hour of reperfusion, spin adduct release was barely detectable (Fig. 3) (four of the eight dogs showed no PBN adduct production at $2 \mathrm{~h}$, and only one dog exhibited adduct production at $4 \mathrm{~h}$ ). There was no release of adducts in any dog at $6 \mathrm{~h}$.
Visual inspection of the observed EPR spectra (Figs. 1 and 2 ) indicates that the signals are likely due to a mixture of different radical adducts. In an effort to gain insights into the number, nature, and relative proportions of these adducts, computer simulation of the spectra was performed, as previously described $(3,4,6)$, on signals obtained early as well as late after reperfusion. The results of this analysis suggest the presence of at least three different components (Fig. 4): component 1, a PBN radical adduct with hyperfine coupling constants $a_{N}$ $=15.2 \mathrm{G}$ and $\mathrm{a}_{\beta}{ }^{\mathrm{H}}=6.0 \mathrm{G}$; component $2, \mathrm{a} \mathrm{PBN}$ radical adduct with $\mathrm{a}_{\mathrm{N}}=14.6 \mathrm{G}$ and $\mathrm{a}_{\beta}{ }^{\mathrm{H}}=3.0 \mathrm{G}$; and component 3 , which is the $\alpha$-tocopheroxyl radical. The combination of components 1 , 2 , and 3 resulted in computer-generated spectra (panels $D, E$, and $F$ of Fig. 1; $C$ and $D$ of Fig. 2) which closely resemble the corresponding observed spectra ( $A, B$, and $C$ of Fig. $1 ; A$ and $B$ of Fig. 2). The three components were observed throughout the reperfusion phase, but their relative proportions varied at different times after release of coronary occlusion, as illustrated in Figs. 1 and 2. For example, during the first minute of reperfusion, components 1 and 2 were present in a ratio of $\sim 1: 1$ (Fig. $1 \mathrm{D}$ ); at 3 and $10 \mathrm{~min}$, the ratio of component 2 to component 1 increased to $\sim 4.4: 1.0$ and 1.5:1.0, respectively (Fig. 1, $E$ and $F$ ), but by $1 \mathrm{~h}$ it decreased to 0.3:1.0 (Fig. $2 D$ ). Component 1 remained the major spin trapped radical after $1 \mathrm{~h}$ (data not shown). Thus, component 2 was the predominant PBN adduct released in the early phase of reperfusion (first $10 \mathrm{~min}$ ), during the burst of free radical generation, whereas component 1 was the predominant PBN adduct released at later times, during the period of low intensity radical production. In some cases the $\alpha$-tocopheroxyl radical (component 3 ) accounted for a large portion of the EPR spectra both early and late after reperfusion (Figs. 1 and 2). In the dog illustrated in Fig. 1, the ratio of this radical to components 1 and 2 was 2.17:1.00:1.00, respectively, at $1 \mathrm{~min}$ of reflow (panel $D$ ) and 3.06:1.00:1.50, respectively, at $10 \mathrm{~min}$ of reflow ( $\operatorname{panel} F$ ). However, $\alpha$-tocopheroxyl radicals were not observed consistently in all samples (Fig. $2 D$ ). Two of the eight dogs showed no $\alpha$-tocopheroxyl radicals at any time point; in the remaining six dogs, $\alpha$-tocopheroxyl radicals were detected in both arterial and venous samples at baseline (before PBN infusion) and/or at subsequent time points. In contrast to the PBN adducts, the presence of $\alpha$-tocopheroxyl radicals in the arterial and venous samples was erratic, with the signals being observed, in the same animal, at some time points but not at others (Fig. 2).

To investigate the physiological significance of the observed $\alpha$-tocopheroxyl radicals, and to determine whether they had any influence on the release of PBN adducts, a statistical analysis was performed using both linear and curvilinear regression models $(21,25)$. At individual time points, there was no correlation between the venous-arterial (transcardiac) difference in $\alpha$-tocopheroxyl signal intensity or the cardiac release of $\alpha$-tocopheroxyl radicals, on one hand, and the following variables, on the other hand: $(a)$ systolic wall thickening; $(b)$ net intensity of PBN adduct signals in the coronary venous plasma; and (c) cardiac release of PBN adducts (all $r<0.25$ ). Furthermore, there was no correlation between the total cumulative venousarterial (transcardiac) difference in $\alpha$-tocopheroxyl signal intensity or the total cumulative release of $\alpha$-tocopheroxyl radicals in the first 5 or 10 min of reperfusion, on one hand, and the following variables, on the other hand: $(a)$ collateral flow during LAD occlusion; $(b)$ systolic wall thickening at 1, 2, 3, 4, 5, or $6 \mathrm{~h}$ of reperfusion; $(c)$ total deficit of wall thickening over the 
Table I. Hemodynamic Variables and Wall Thickening in Groups I and III*

\begin{tabular}{|c|c|c|c|c|c|c|c|c|}
\hline & \multirow[b]{3}{*}{ Baseline } & \multirow[b]{3}{*}{ Occlusion } & \multicolumn{6}{|c|}{ Reperfusion } \\
\hline & & & & & $h$ & & & \\
\hline & & & 1 & 2 & 3 & 4 & 5 & 6 \\
\hline \multicolumn{9}{|c|}{$\mathrm{HR}$ (beats/min) } \\
\hline Group I & $142 \pm 9$ & $156 \pm 6$ & $151 \pm 8$ & $144 \pm 9$ & $142 \pm 9$ & $141 \pm 10$ & $145 \pm 12$ & $150 \pm 8$ \\
\hline Group III & $113 \pm 8^{\ddagger}$ & $149 \pm 8$ & $121 \pm 8^{\ddagger}$ & $117 \pm 7^{\ddagger}$ & $122 \pm 8$ & $118 \pm 6^{\ddagger}$ & $124 \pm 8$ & $113 \pm 7^{\ddagger}$ \\
\hline \multicolumn{9}{|c|}{ MAP $(m m H g)$} \\
\hline Group I & $97 \pm 5$ & $94 \pm 6$ & $95 \pm 5$ & $96 \pm 6$ & $96 \pm 5$ & $95 \pm 6$ & $95 \pm 6$ & $95 \pm 5$ \\
\hline Group III & $110 \pm 5^{\ddagger}$ & $114 \pm 4^{\ddagger}$ & $112 \pm 4^{\ddagger}$ & $111 \pm 5$ & $114 \pm 4^{\ddagger}$ & $112 \pm 4^{\ddagger}$ & $109 \pm 4$ & $104 \pm 4$ \\
\hline \multicolumn{9}{|l|}{ LAP $(m m H g)$} \\
\hline Group I & $9.2 \pm 1.3$ & $12.4 \pm 2.5$ & $8.6 \pm 0.8$ & $10.0 \pm 1.8$ & $9.4 \pm 1.9$ & $10.2 \pm 2.7$ & $9.8 \pm 2.9$ & $11.8 \pm 3.5$ \\
\hline Group III & $7.0 \pm 1.0$ & $11.4 \pm 1.4$ & $7.6 \pm 0.9$ & $7.1 \pm 0.8$ & $7.5 \pm 0.8$ & $6.7 \pm 0.8$ & $7.0 \pm 0.9$ & $6.7 \pm 0.7$ \\
\hline \multicolumn{9}{|c|}{ Normalized LAD flow ( $\mathrm{ml} / \mathrm{min}$ per $g$ ) } \\
\hline Group I & $1.31 \pm 0.48$ & 0 & $1.44 \pm 0.60$ & $1.50 \pm 0.62$ & $1.55 \pm 0.66$ & $1.57 \pm 0.61$ & $1.44 \pm 0.73$ & $1.71 \pm 0.97$ \\
\hline Group III & $1.62 \pm 0.23$ & 0 & $1.71 \pm 0.20$ & $1.70 \pm 0.20$ & $1.66 \pm 0.21$ & $1.65 \pm 0.21$ & $1.72 \pm 0.20$ & $1.75 \pm 0.22$ \\
\hline \multicolumn{9}{|c|}{$\mathrm{LV} \mathrm{d} P / \mathrm{d} t_{\max }(m m H g / s)$} \\
\hline Group I & $3257 \pm 418$ & $3071 \pm 393$ & $2968 \pm 443$ & $3093 \pm 451$ & $3134 \pm 537$ & $3430 \pm 466$ & $3524 \pm 524$ & $2933 \pm 455$ \\
\hline Group III & $3260 \pm 163$ & $3281 \pm 233$ & $3122 \pm 195$ & $2911 \pm 129$ & $3069 \pm 191$ & $3059 \pm 179$ & $3142 \pm 190$ & $3040 \pm 170$ \\
\hline \multicolumn{9}{|c|}{$\mathrm{LV} \mathrm{d} P / \mathrm{d} t_{\min }(m m H g / s)$} \\
\hline Group I & $3243 \pm 321$ & $2825 \pm 435$ & $2933 \pm 427$ & $2995 \pm 473$ & $3152 \pm 546$ & $3214 \pm 514$ & $3291 \pm 580$ & $2608 \pm 176$ \\
\hline Group III & $3292 \pm 138$ & $3175 \pm 188$ & $3048 \pm 151$ & $2964 \pm 153$ & $3027 \pm 164$ & $2964 \pm 175$ & $3017 \pm 191$ & $2822 \pm 149$ \\
\hline \multicolumn{9}{|l|}{$\operatorname{ThF}(\mathrm{IZ})(\%)$} \\
\hline Group I & $100 \pm 0$ & $-41.4 \pm 8.1$ & $53.3 \pm 27.0$ & $74.5 \pm 14.5$ & $73.6 \pm 14.4$ & $93.5 \pm 14.3$ & $86.6 \pm 19.2$ & $108.3 \pm 20.2$ \\
\hline Group III & $100 \pm 0$ & $-38.8 \pm 7.9$ & $-20.1 \pm 12.8$ & $35.6 \pm 11.7$ & $47.2 \pm 11.2$ & $54.5 \pm 10.8$ & $62.4 \pm 10.0$ & $70.4 \pm 6.0^{\ddagger}$ \\
\hline \multicolumn{9}{|c|}{$\operatorname{ThF}(\mathrm{NIZ})(\%)$} \\
\hline Group I & 100 & $90.3 \pm 7.3$ & $104.5 \pm 4.5$ & $105.1 \pm 5.8$ & $103.3 \pm 5.3$ & $107.1 \pm 8.2$ & $101.7 \pm 7.8$ & $106.5 \pm 8.3$ \\
\hline Group III & 100 & $95.2 \pm 5.2$ & $105.2 \pm 7.6$ & $105.7 \pm 7.3$ & $107.6 \pm 7.3$ & $107.1 \pm 5.8$ & $111.0 \pm 6.4$ & $112.3 \pm 5.9$ \\
\hline
\end{tabular}

Data are mean \pm SEM. Abbreviations: HR, heart rate; MAP, mean arterial pressure; LAP, mean left atrial pressure; normalized LAD flow, coronary blood flow in the left anterior descending artery normalized to the weight of the occluded/reperfused bed; $\mathrm{LV} \mathrm{d} P / \mathrm{d} t_{\max }, \operatorname{maximal} \mathrm{rate}$ of left ventricular pressure rise; $\mathrm{LV} \mathrm{d} / \mathrm{d} t_{\text {min }}$, maximal rate of left ventricular pressure fall; ThF (IZ), systolic thickening fraction in the ischemic/ reperfused zone (expressed as percentage of baseline values); ThF (NIZ), systolic thickening fraction in the nonischemic (control) zone (expressed as percentage of baseline values). Baseline measurements were taken 20 min before occlusion ( 15 min before starting PBN infusion). At baseline, systolic thickening fraction in the ischemic zone was $17.4 \pm 2.2 \%$ in group I and $19.5 \pm 1.7 \%$ in group III; the corresponding values in the nonischemic zone were $16.1 \pm 1.5 \%$ in group I and $19.3 \pm 1.4 \%$ in group III. ${ }^{*}$ In group I $(n=8)$, infusion of PBN was started 5 min before ischemia and continued until $10 \mathrm{~min}$ after reperfusion; in group III $(n=13)$ no PBN was given. ${ }^{\ddagger} P<0.05$ vs. group I.

Table II. Regional Myocardial Blood Flow in Groups I and III*

\begin{tabular}{|c|c|c|c|c|c|c|}
\hline & \multicolumn{3}{|c|}{ Ischemic zone } & \multicolumn{3}{|c|}{ Nonischemic zone } \\
\hline & Epi & Endo & Mean & Epi & Endo & Mean \\
\hline \multicolumn{7}{|c|}{ Baseline ( $\mathrm{ml} / \mathrm{min}$ per $\mathrm{g})$} \\
\hline Group I & $1.27 \pm 0.07$ & $1.41 \pm 0.12$ & $1.34 \pm 0.09$ & $1.30 \pm 0.12$ & $1.80 \pm 0.12$ & $1.55 \pm 0.12$ \\
\hline Group III & $1.15 \pm 0.09$ & $1.41 \pm 0.11$ & $1.28 \pm 0.09$ & $1.21 \pm 0.10$ & $1.46 \pm 0.10$ & $1.34 \pm 0.10$ \\
\hline \multicolumn{7}{|c|}{$\operatorname{Occlusion}^{\ddagger}(\mathrm{ml} / \mathrm{min}$ per $\mathrm{g})$} \\
\hline Group I & $0.37 \pm 0.17$ & $0.26 \pm 0.14$ & $0.32 \pm 0.16$ & $1.43 \pm 0.14$ & $1.89 \pm 0.19$ & $1.66 \pm 0.16$ \\
\hline $\begin{array}{l}\text { Group III } \\
(\% N Z F)\end{array}$ & $0.34 \pm 0.06$ & $0.16 \pm 0.04$ & $0.25 \pm 0.05$ & $1.43 \pm 0.11$ & $1.69 \pm 0.12$ & $1.56 \pm 0.12$ \\
\hline Group I & - & - & $22.4 \pm 11.3$ & - & - & - \\
\hline Group III & - & - & $18.7 \pm 3.9$ & - & - & - \\
\hline
\end{tabular}

Values are mean \pm SEM. Abbreviations: Endo, endocardial flow; Epi; epicardial flow; Mean, mean transmural flow; NZF, simultaneous nonischemic zone flow. * In group I $(n=8)$, infusion of PBN was started 5 min before ischemia and continued until 10 min after reperfusion; in group III $(n=13)$ no PBN was given. ${ }^{\ddagger}$ Blood flow to the ischemic zone during coronary occlusion is expressed both in absolute terms (ml/min per $\mathrm{g}$ ) and as a percentage of NZF. 


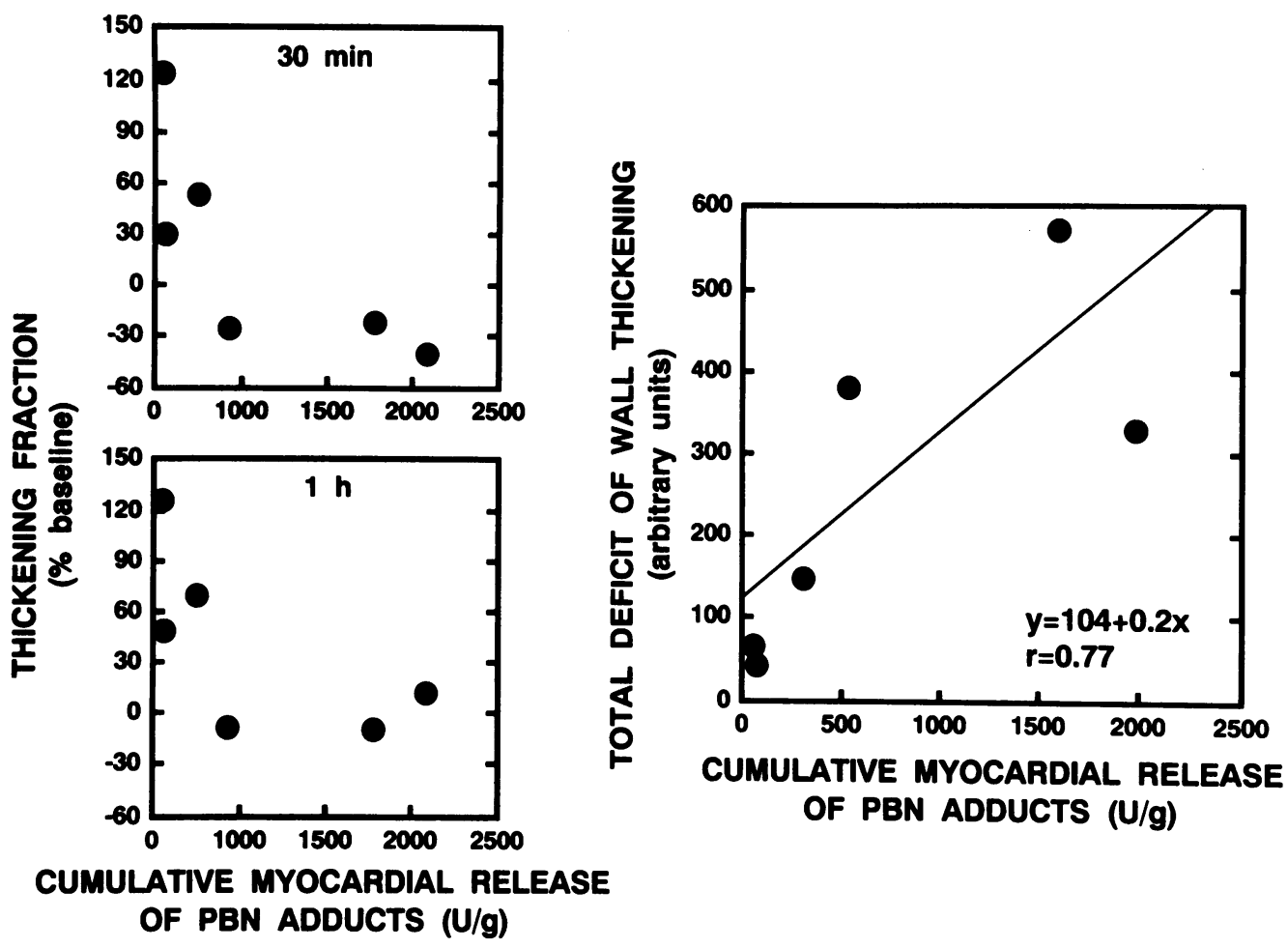

Figure 6. Relationship between total cumulative myocardial release of PBN adducts during the first $10 \mathrm{~min}$ of reperfusion (horizontal axis) and: (a) systolic thickening fraction at $30 \mathrm{~min}$ of reperfusion (left, upper panel), (b) systolic thickening fraction at $1 \mathrm{~h}$ of reperfusion (left, lower panel), (c) total cumulative deficit of wall thickening during the first $6 \mathrm{~h}$ of reperfusion (right panel) (vertical axis) in group I. Adduct release is expressed in arbitrary units per gram of myocardium (see text for explanation of units); thickening fraction is expressed as a percentage of baseline values; deficit of wall thickening is expressed in arbitrary units (see text for explanation). There was an inverse relationship between release of PBN adducts and thickening fraction at $30 \mathrm{~min}$ $(Y=62.7-0.057 X, r$

$=-0.75)$ and at $1 \mathrm{~h}(Y=77.9-0.046 X, r=-0.65)$ of reperfusion. In addition, there was a direct relationship between release of PBN adducts and total deficit of function during the subsequent $6 \mathrm{~h}(Y=104+0.2 X, r=0.77)$. Thus, the greater the production of radicals early after reflow, the greater the ensuing loss of contractility.

first $6 \mathrm{~h}$ of reperfusion; and $(d)$ cumulative cardiac release of PBN adducts in the first 10 min of reperfusion (all $r$ values $<0.30$ ). The largest postischemic deficit of function was observed in one of the two dogs that exhibited no $\alpha$-tocopheroxyl radicals. In conclusion, the release of vitamin $\mathrm{E}$ radicals was unrelated to the release of PBN adducts and also did not correlate with either the severity of ischemia or the severity of postischemic dysfunction.

In group II (control dogs that received PBN but did not undergo ischemia/reperfusion), no release of PBN adducts from the LAD territory was observed at any time point during or after the infusion of PBN. (The blood samples were collected at times corresponding to those in group I). As in group I, $\alpha$-tocopheroxyl radicals were noted in some of the arterial and venous samples, with no consistent pattern.

Plasma concentration and pharmacokinetics of $P B N$. The concentration of PBN in the arterial plasma was measured in all eight dogs in group I and was found to be reasonably stable during the first $10 \mathrm{~min}$ of reperfusion, averaging $300 \pm 20 \mu \mathrm{M}$ at $2 \mathrm{~min}, 312 \pm 21 \mu \mathrm{M}$ at $5 \mathrm{~min}$, and $362 \pm 24 \mu \mathrm{M}$ at $10 \mathrm{~min}$. Furthermore, the plasma levels of PBN were reasonably consistent in different dogs (as indicated by the narrow standard errors), with individual values ranging from 224 to $396 \mu \mathrm{M}$ at $2 \mathrm{~min}$, from 235 to $404 \mu \mathrm{M}$ at $5 \mathrm{~min}$, and from 269 to $440 \mu \mathrm{M}$ at 10 min. Thus, the marked variability in spin adduct release among individual animals which is described below (see Figs. $5,6,9$, and 10) cannot be ascribed to individual differences in the concentration of PBN in the arterial blood. PBN continued to be present in the blood for several hours after the infusion was discontinued. At $2 \mathrm{~h}$ of reperfusion (when PBN adduct production had ceased almost completely), the PBN plasma concentration averaged $138 \pm 18 \mu \mathrm{M}(46 \%$ of the 2 -min values), at $4 \mathrm{~h} 91 \pm 19 \mu \mathrm{M}$ ( $30 \%$ of the 2 -min values), and at $6 \mathrm{~h}$ $56 \pm 10 \mu \mathrm{M}$ ( $19 \%$ of the 2 -min values).

In a separate group of six conscious dogs, the pharmacokinetics of PBN were found to be as follows: terminal elimination half-life, $190.0 \pm 33.9 \mathrm{~min}$; peak plasma concentration, $348.2 \pm 29.7 \mu \mathrm{M}$; mean residence time, $268.8 \pm 49.3 \mathrm{~min}$; clearance, $0.1279 \pm 0.0237 \mathrm{liter} / \mathrm{min}$; and apparent volume of distribution during the terminal elimination phase, $1.18 \pm 0.04$ liter $/ \mathrm{kg}$.

Relation between PBN adduct release and severity of ischemia. Fig. 5 illustrates the relationship between collateral flow during coronary occlusion and total cumulative release of PBN adducts during the initial $10 \mathrm{~min}$ of reperfusion (interval corresponding to the burst of adduct production ) in group I. Despite the relatively similar plasma levels of PBN (see above), it is evident that the myocardial release of spin trapped radicals exhibited a marked individual variability, ranging from 48 to $1,988 \mathrm{U} / \mathrm{g}$. When all eight dogs were considered, an inverse overall relationship between PBN adduct production and collateral flow was found ( $r=0.67$ using an exponential regression model detailed in the legend to Fig. 5 ). The distribution of data in Fig. 5, however, can be more appropriately described as a "threshold phenomenon": little or no free radical production was observed in the two dogs with collateral flow $>30-40 \%$ of nonischemic zone flow, whereas in the six dogs below this threshold of collateral flow, radical production did not correlate significantly with flow (although five of the six dogs were in a narrow range of collateral flow [ $1-8 \%$ of nonischemic zone 
flow], which would make it difficult to demonstrate a significant correlation). These data indicate that the intensity of the burst of free radical generation associated with reperfusion is highly variable, and that the severity of the antecedent ischemic insult is an important determinant of whether radical production occurs: PBN-trapped free radicals appear to be formed only when ischemic flow falls below a threshold value $(\sim 30-$ $40 \%$ of nonischemic flow).

Relation between PBN adduct release and severity of postischemic dysfunction. Fig. 6 demonstrates the relationship between the total cumulative release of PBN adducts during the initial $10 \mathrm{~min}$ of reperfusion and $(a)$ the systolic thickening fraction at $30 \mathrm{~min}$ and $1 \mathrm{~h}$ of reflow and $(b)$ the total deficit of wall thickening over the first $6 \mathrm{~h}$ of reperfusion. The total postreperfusion deficit of wall thickening was calculated by measuring, with a computerized program, the area comprised between the thickening-vs.-time line and the baseline ( $100 \%$ line) over the 6-h period of observation after reflow (21). (This measurement integrates the deficit of function observed at individual time points and, therefore, reflects the magnitude of postischemic dysfunction more accurately than single time point measurements [21]). The severity of myocardial stunning was found to vary markedly from dog to dog (Fig. 6); however, there was an inverse relationship between the myocardial release of PBN adducts during the first 10 min of reperfusion and the thickening fraction measured at $30 \mathrm{~min}$ and $1,2,3,4,5$, and $6 \mathrm{~h}$ of reperfusion $(r=-0.75,-0.65,-0.72,-0.75,-0.58$, -0.84 , and -0.94 , respectively [Fig. 6]; the correlations at 2, 3, 4,5 , and $6 \mathrm{~h}$ are not shown in Fig. 6 for the sake of brevity). In addition, there was a direct relationship between the myocardial production of PBN adducts during the initial $10 \mathrm{~min}$ of reperfusion and the cumulative deficit of function observed over the ensuing $6 \mathrm{~h}(Y=104+0.2 X, r=0.77)$ (Fig. 6). These results indicate that the intensity of radical generation immediately after reflow presages the extent and duration of the subsequent functional depression: the greater the production of radicals, the greater the loss of contractility.

Effect of $P B N$ on recovery of contractile function. To determine whether PBN attenuates postischemic dysfunction in the conscious dog, the 8 animals in group I (which received PBN) were compared with 13 control dogs that did not receive PBN (group III). There was no significant difference between groups I and III with respect to blood flow in the LAD territory before or during occlusion (Table II). The size of the occluded vascular bed was also similar: $24.7 \pm 1.7 \mathrm{~g}$ in group I and $25.0 \pm 1.4 \mathrm{~g}$ in group III $(28.2 \pm 1.5 \%$ and $26.8 \pm 1.1 \%$ of $\mathrm{LV}$ weight, respectively). Systolic thickening fraction in the nonischemic (control) region did not differ significantly between the two groups at any time point during the protocol (Table I). Systolic thickening fraction in the LAD-dependent region was also similar in PBN-treated and in control dogs at baseline (17.4 $\pm 2.2 \%$ vs. $19.5 \pm 1.7 \%$, respectively) and during coronary occlusion $(-41.4 \pm 8.1$ vs. $-38.8 \pm 7.9 \%$, respectively). After reperfusion, the measurements of wall thickening were greater in group I than in group III but the differences achieved statistical significance only at $6 \mathrm{~h}$ (Table I). The total deficit of wall thickening during the first $6 \mathrm{~h}$ of reperfusion was $44 \%$ smaller in group I as compared with group III. Since PBN in effect acts as a free radical scavenger, the finding that it enhanced the postischemic recovery of function in conscious dogs further corroborates the hypothesis the free radicals contribute to myocardial stunning.
Plasma and myocardial concentration of $\alpha$-tocopherol. The concentration of $\alpha$-tocopherol was found to average $20.8 \pm 1.5$ $\mu \mathrm{M}$ (range 16.6-25.0) in the arterial plasma and $0.206 \pm 0.017$ $\mathrm{nmol} / \mathrm{mg}$ of protein (range $0.171-0.279$ ) in the LV myocardium. The concentration of $\alpha$-tocopherol quinone was below detection limits in the arterial plasma and $0.005 \pm 0.001 \mathrm{nmol} /$ $\mathrm{mg}$ of protein in the LV myocardium. The relatively low coefficients of variation for plasma and tissue levels of $\alpha$-tocopherol ( $17.3 \%$ and $20.9 \%$, respectively) make it unlikely that the variability in PBN adduct production (Fig. 5) and wall thickening (Fig. 6) can be explained by differences in $\alpha$-tocopherol status.

\section{Part II. Comparison of anesthetized and conscious dogs}

In part II of this study, the conscious dogs in group I were compared with a group of pentobarbital-anesthetized, openchest dogs subjected to the same duration of ischemia (a 15min LAD occlusion). The techniques used to measure free radicals, wall thickening, and other variables were identical in the two groups.

Exclusions. Of the 15 dogs anesthetized for the studies of free radical production and wall thickening, 4 (27\%) were excluded because of technical problems during instrumentation ( 2 dogs) and ventricular fibrillation after reperfusion ( 2 dogs). Thus, analysis of data was carried out in 11 open-chest dogs. Two separate groups of 7 and 10 dogs were used for the assessment of PBN pharmacokinetics and for the measurement of $\alpha$-tocopherol, respectively; none of these dogs was excluded.

Arterial blood gases, hematocrit, and temperature. These variables were within physiological limits throughout the protocol. The following measurements were obtained at baseline and at $1 \mathrm{~h}$ after reperfusion, respectively: arterial $\mathrm{pH}$, $7.40 \pm 0.01$ and $7.36 \pm 0.02$; arterial $\mathrm{Po}_{2}, 103 \pm 9$ and $98 \pm 8$ $\mathrm{mmHg}$; hematocrit, $38.2 \pm 3.7 \%$ and $30.5 \pm 2.2 \%$. Esophageal temperature averaged $37.8 \pm 0.2^{\circ} \mathrm{C}$ at baseline, $37.6 \pm 0.2^{\circ} \mathrm{C}$ at 1 $\mathrm{h}$ of reperfusion, and $37.6 \pm 0.2^{\circ} \mathrm{C}$ at $3 \mathrm{~h}$ of reperfusion.

Hemodynamic variables. Compared with the conscious dogs (group I), the open-chest dogs exhibited significantly lower left atrial pressures throughout the experiment (Table III); peak positive $\mathrm{d} P / \mathrm{d} t$ at baseline and during occlusion and arterial pressure during occlusion were also significantly lower than in conscious dogs ( Table III). There were no other significant differences between the two groups.

Occluded bed size and regional myocardial blood flow. The size of the occluded vascular bed did not differ significantly in conscious and open-chest dogs: $24.7 \pm 1.7 \mathrm{~g}(28.2 \pm 1.5 \%$ of $\mathrm{LV}$ weight) and $21.2 \pm 2.5 \mathrm{~g}(23.6 \pm 2.1 \%$ of $\mathrm{LV}$ weight $)$, respectively. Regional myocardial blood flow during LAD occlusion was also similar in the two groups (Table IV).

Myocardial production of $P B N$ adducts. Similarly to the pattern observed in conscious dogs (group I), open-chest dogs exhibited a burst of PBN adduct release during the initial minutes of reperfusion (Fig. 7). There were, however, some major differences between the two groups. First, the release of spin adducts was considerably greater in open-chest dogs throughout the reperfusion phase (Fig. 7). Second, unlike the conscious animals, in which the production of adducts ceased almost completely after the first hour of reflow, the anesthetized animals showed substantial adduct production throughout the $3 \mathrm{~h}$ of reperfusion; at $3 \mathrm{~h}$, the release of adducts in these dogs was still $\sim 30 \%$ of the values measured in the first $3 \mathrm{~min}$ of reflow and $43 \%$ of the values measured at $10 \mathrm{~min}$ of reflow (Fig. 7). As a result of these differences between the two 


\begin{tabular}{|c|c|c|c|c|c|c|}
\hline & \multirow[b]{2}{*}{ Baseline } & \multirow[b]{2}{*}{ Occlusion } & \multicolumn{4}{|c|}{ Reperfusion } \\
\hline & & & $30 \mathrm{~min}$ & 1 & $\begin{array}{l}h \\
2\end{array}$ & 3 \\
\hline \multicolumn{7}{|l|}{ HR (beats/min) } \\
\hline Conscious & $142 \pm 9$ & $156 \pm 6$ & $147 \pm 7$ & $151 \pm 8$ & $144 \pm 9$ & $142 \pm 9$ \\
\hline Open-chest & $145 \pm 3$ & $149 \pm 6$ & $148 \pm 7$ & $147 \pm 7$ & $151 \pm 5$ & $154 \pm 5$ \\
\hline \multicolumn{7}{|l|}{$\mathrm{SAP}(m m H g)$} \\
\hline Conscious & $125 \pm 5$ & $120 \pm 5$ & $117 \pm 4$ & $122 \pm 4$ & $120 \pm 5$ & $116 \pm 4$ \\
\hline Open-chest & $127 \pm 6$ & $128 \pm 5$ & $129 \pm 6$ & $127 \pm 8$ & $123 \pm 6$ & $121 \pm 5$ \\
\hline \multicolumn{7}{|c|}{$\mathrm{RPP}(H R \times$ systolic pressure $/ 1000)$} \\
\hline Conscious & $17.6 \pm 1.4$ & $18.8 \pm 1.1$ & $17.2 \pm 0.9$ & $18.4 \pm 1.1$ & $17.3 \pm 1.3$ & $16.5 \pm 1.1$ \\
\hline Open-chest & $18.4 \pm 0.9$ & $18.9 \pm 0.7$ & $18.8 \pm 0.9$ & $18.3 \pm 1.0$ & $18.4 \pm 0.8$ & $18.5 \pm 0.8$ \\
\hline \multicolumn{7}{|l|}{ MAP $(m m H g)$} \\
\hline Conscious & $97 \pm 5$ & $94 \pm 6^{\ddagger}$ & $95 \pm 5$ & $95 \pm 5$ & $96 \pm 6$ & $96 \pm 5$ \\
\hline Open-chest & $112 \pm 6$ & $112 \pm 5$ & $109 \pm 6$ & $109 \pm 7$ & $104 \pm 5$ & $101 \pm 5$ \\
\hline \multicolumn{7}{|l|}{$\operatorname{LAP}(m m H g)$} \\
\hline Conscious & $9.2 \pm 1.3^{\ddagger}$ & $12.4 \pm 2.5^{\ddagger}$ & $8.3 \pm 0.9^{\ddagger}$ & $8.6 \pm 0.8^{\ddagger}$ & $10.0 \pm 1.8^{\ddagger}$ & $9.4 \pm 1.9^{\ddagger}$ \\
\hline Open-chest & $4.7 \pm 0.8$ & $5.8 \pm 1.1$ & $5.2 \pm 0.5$ & $4.0 \pm 0.7$ & $4.5 \pm 0.7$ & $4.0 \pm 0.9$ \\
\hline \multicolumn{7}{|c|}{ Normalized LAD flow ( $\mathrm{ml} / \mathrm{min}$ per $\mathrm{g}$ ) } \\
\hline Conscious & $1.31 \pm 0.48$ & 0 & $1.56 \pm 0.61$ & $1.44 \pm 0.60$ & $1.50 \pm 0.62$ & $1.55 \pm 0.66$ \\
\hline Open-chest & $1.39 \pm 0.23$ & 0 & $1.25 \pm 0.20$ & $1.08 \pm 0.20$ & $1.20 \pm 0.16$ & $1.25 \pm 0.16$ \\
\hline \multicolumn{7}{|c|}{$\mathrm{LV} \mathrm{d} P / \mathrm{d} t_{\max }(m m H g / s)$} \\
\hline Conscious & $3257 \pm 418^{\ddagger}$ & $3071 \pm 393^{\ddagger}$ & $2846 \pm 435$ & $2968 \pm 443$ & $3093 \pm 451$ & $3134 \pm 537$ \\
\hline Open-chest & $1980 \pm 133$ & $2125 \pm 182$ & $2032 \pm 171$ & $2105 \pm 172$ & $2219 \pm 225$ & $2255 \pm 188$ \\
\hline \multicolumn{7}{|c|}{$\mathrm{LV} \mathrm{d} P / \mathrm{d} t_{\min }(m m H g / s)$} \\
\hline Conscious & $3243 \pm 321$ & $2825 \pm 435$ & $2965 \pm 513$ & $2933 \pm 427$ & $2995 \pm 473$ & $3152 \pm 546$ \\
\hline Open-chest & $2954 \pm 300$ & $2613 \pm 261$ & $2577 \pm 312$ & $2541 \pm 332$ & $2515 \pm 338$ & $2517 \pm 343$ \\
\hline \multicolumn{7}{|l|}{ ThF (NIZ) (\%) } \\
\hline Conscious & 100 & $90.3 \pm 7.3$ & $94.3 \pm 3.9$ & $104.5 \pm 4.5$ & $105.1 \pm 5.8$ & $103.3 \pm 5.3$ \\
\hline Open-chest & 100 & $104.3 \pm 9.6$ & $91.2 \pm 7.4$ & $86.3 \pm 8.7$ & $89.8 \pm 6.2$ & $91.7 \pm 8.3$ \\
\hline
\end{tabular}

Data are mean \pm SEM. Abbreviations: HR, heart rate; SAP, systolic arterial pressure; RPP, rate-pressure product; MAP, mean arterial pressure; LAP, mean left atrial pressure; normalized LAD flow, coronary blood flow in the left anterior descending artery normalized to the weight of the occluded/reperfused bed; $\mathrm{LV} \mathrm{d} P / \mathrm{d} t_{\max }$, maximal rate of left ventricular pressure rise; $\mathrm{LV} \mathrm{d} P / \mathrm{d} t_{\min }$, maximal rate of left ventricular pressure fall; $\mathrm{ThF}$ (NIZ), systolic thickening fraction in the nonischemic (control) zone (expressed as percentage of baseline values). Baseline measurements were taken $20 \mathrm{~min}$ before occlusion (15 min before starting PBN infusion). At baseline, systolic thickening fraction in the nonischemic zone was $16.1 \pm 1.5 \%$ in conscious dogs and $18.5 \pm 1.9 \%$ in open-chest dogs. ${ }^{*}$ Both conscious $(n=8)$ and open-chest $(n=11)$ dogs received an infusion of PBN starting 5 min before ischemia and ending $10 \mathrm{~min}$ after reperfusion. ${ }^{\ddagger} P<0.05$ vs. open-chest dogs.

Table IV. Regional Myocardial Blood Flow during Coronary Occlusion in Conscious (Group I) and Open-Chest Dogs*

\begin{tabular}{|c|c|c|c|c|c|c|}
\hline & \multicolumn{3}{|c|}{ Ischemic zone } & \multicolumn{3}{|c|}{ Nonischemic zone } \\
\hline & Epi & Endo & Mean & Epi & Endo & Mean \\
\hline \multicolumn{7}{|l|}{$(\mathrm{ml} / \mathrm{min} \text { per } g)^{\ddagger}$} \\
\hline Conscious & $0.37 \pm 0.17$ & $0.26 \pm 0.14$ & $0.32 \pm 0.16$ & $1.43 \pm 0.14$ & $1.89 \pm 0.19$ & $1.66 \pm 0.16$ \\
\hline Open-chest & $0.47 \pm 0.12$ & $0.24 \pm 0.05$ & $0.32 \pm 0.07$ & $1.59 \pm 0.19$ & $1.76 \pm 0.18$ & $1.68 \pm 0.16$ \\
\hline \multicolumn{7}{|l|}{$\left(\% N Z F^{\ddagger}\right)$} \\
\hline Conscious & - & - & $22.4 \pm 11.3$ & - & - & - \\
\hline Open-chest & - & - & $23.1 \pm 7.1$ & - & - & - \\
\hline
\end{tabular}

Values are mean \pm SEM. Abbreviations: Endo, endocardial flow; Epi, epicardial flow; Mean, mean transmural flow; NZF, simultaneous nonischemic zone flow. ${ }^{*}$ Both conscious $(n=8)$ and open-chest $(n=11)$ dogs received an infusion of PBN starting 5 min before ischemia and ending $10 \mathrm{~min}$ after reperfusion. ${ }^{\ddagger}$ Blood flow to the ischemic zone during coronary occlusion is expressed both in absolute terms (ml/min per g) and as a percentage of NZF. 


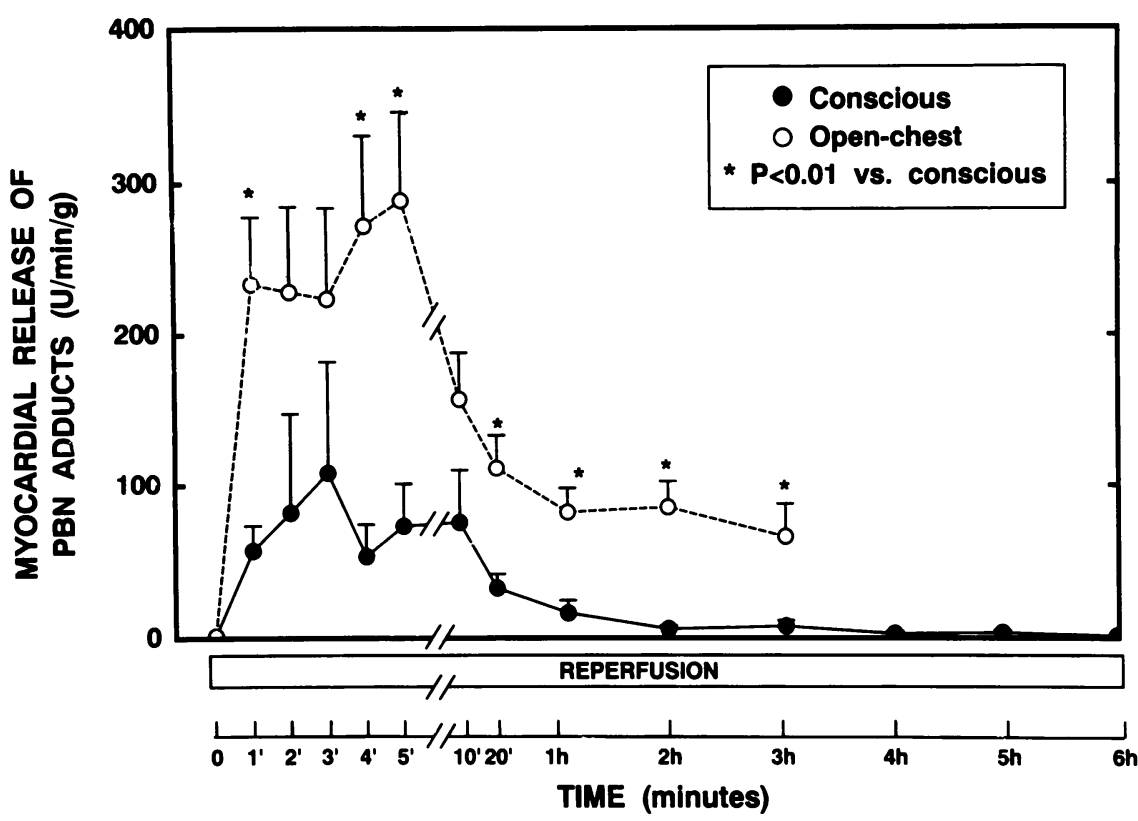

Figure 7. Time course of myocardial release of PBN adducts in conscious dogs (group I, $n$ $=8 ; \bullet)$ and in pentobarbital-anesthetized, open-chest dogs $(n=11 ; 0)$. Data are mean \pm SEM. See text for explanation of units used. groups, the cumulative release of adducts was considerably greater in anesthetized compared with awake dogs during the first $5 \mathrm{~min}, 10 \mathrm{~min}$, and $3 \mathrm{~h}$ of reperfusion: the ratio between the cumulative adduct release in the two models was $\sim 3: 1$ after $5 \mathrm{~min}, 3.5: 1$ after $10 \mathrm{~min}$, and 5:1 after $3 \mathrm{~h}$ (Fig. 8). The EPR spectra observed in open-chest dogs (not shown for the sake of brevity) were similar to those seen in conscious dogs. The results of the analysis of the $\alpha$-tocopheroxyl radicals and the relationship of these radicals to other variables were similar to those reported above for conscious dogs.

Plasma concentration and pharmacokinetics of $P B N$. The concentration of PBN in the arterial plasma (measured in 7 of the 11 dogs) was similar to that observed in the conscious dogs: $301 \pm 44 \mu \mathrm{M}$ at $2 \mathrm{~min}$ of reperfusion, $305 \pm 39 \mu \mathrm{M}$ at $5 \mathrm{~min}$, $323 \pm 34 \mu \mathrm{M}$ at $10 \mathrm{~min}$, and $84 \pm 13 \mu \mathrm{M}$ at $2 \mathrm{~h}$. The pharmacokinetics of PBN (assessed in a separate group of seven open-chest dogs) were found to be similar to those in conscious dogs: terminal elimination half-life, $189.8 \pm 4.8 \mathrm{~min}$; peak plasma concen-

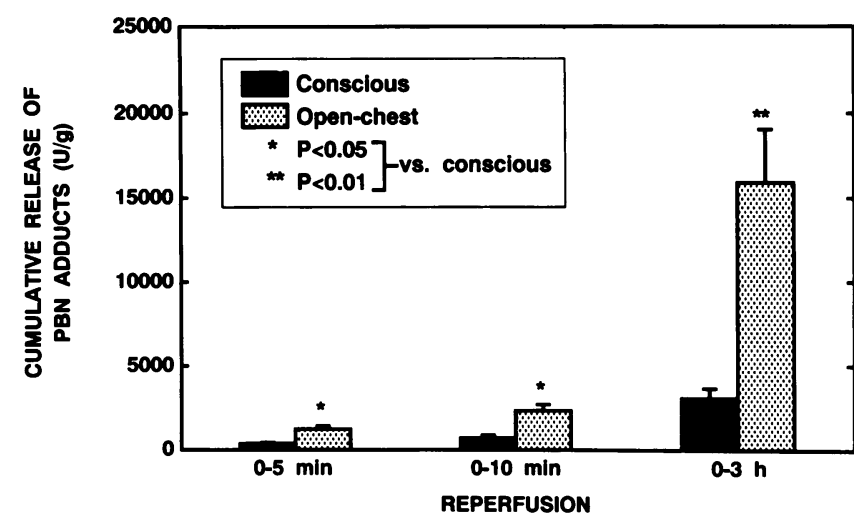

Figure 8. Total cumulative myocardial release of PBN adducts during the first $5 \mathrm{~min}, 10 \mathrm{~min}$, and $3 \mathrm{~h}$ of reperfusion in conscious dogs (group I, $n=8$; solid bars) and in pentobarbital-anesthetized, openchest dogs ( $n=11$; stippled bars $)$. The cumulative release of PBN adducts is expressed in arbitrary units per gram of myocardium (see text for explanation). Data are mean \pm SEM. tration, 338.6 $\pm 41.4 \mu \mathrm{M}$; mean residence time, $263.9 \pm 6.7 \mathrm{~min}$; clearance, $0.1282 \pm 0.0181 \mathrm{liter} / \mathrm{min}$, and apparent volume of distribution during the terminal elimination phase, $1.51 \pm 0.21$ liter $/ \mathrm{kg}$. Thus, the differences in PBN adduct production (Fig. 7) and wall thickening (see Fig. 11) between open-chest and awake dogs cannot be ascribed to differences in PBN plasma levels or pharmacokinetics.

Relation between PBN adduct release and severity of ischemia. The total cumulative release of $\mathrm{PBN}$ adducts during the first 10 min of reperfusion varied markedly and was inversely related to the collateral flow during occlusion $(r=-0.72)$ (Fig. 9 ). For any given level of collateral flow, the release of adducts was greater in anesthetized animals than in conscious dogs (Fig. 9). Similar differences were found when the total adduct production over the first $5 \mathrm{~min}$ or $3 \mathrm{~h}$ of reflow was compared (data not shown).

Relation between PBN adduct release and severity of postischemic dysfunction. Unlike the conscious dogs, in the openchest dogs there was no relation between the cumulative release of adducts during the first $10 \mathrm{~min}$ of reflow and $(a)$ the thickening fraction at $30 \mathrm{~min}, 1 \mathrm{~h}, 2 \mathrm{~h}$, and $3 \mathrm{~h}$ of reperfusion, or $(b)$ the total deficit of wall thickening over the first $3 \mathrm{~h}$ of reflow (all $r$ values $<0.40$; in Fig. 10 the data at 2 and $3 \mathrm{~h}$ are not shown for the sake of brevity). Similar results were obtained when cumulative adduct production was measured over the first 5 min or $180 \mathrm{~min}$ of reperfusion (data not shown).

Recovery of contractile function. Systolic thickening fraction in the nonischemic (control) region did not differ significantly between conscious and open-chest dogs (Table III). Baseline systolic thickening fraction in the region to be rendered ischemic was also similar: $17.4 \pm 2.2 \%$ in conscious dogs and $19.1 \pm 2.4 \%$ in anesthetized animals. After reperfusion, however, the recovery of contractile function was considerably greater in conscious dogs, and these differences were statistically significant at 2 and $3 \mathrm{~h}$ (Fig. 11). The total deficit of wall thickening during the first $3 \mathrm{~h}$ of reflow was $52 \%$ less in conscious compared with open-chest dogs; that is, the postischemic functional depression associated with the anesthetized model was more than twice that observed in the awake model. 


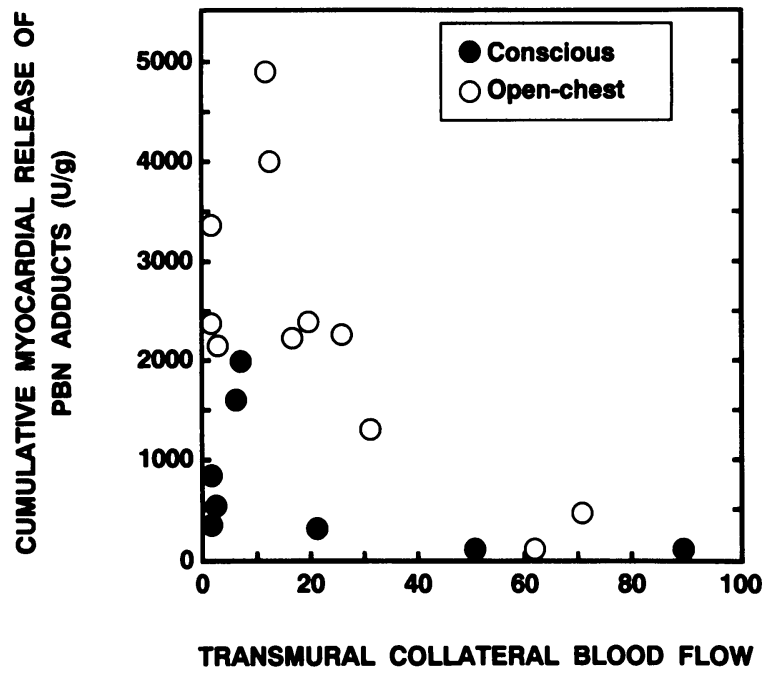

(\% Nonischemic zone flow)

Figure 9. Relationship between mean transmural collateral blood flow to the ischemic region during coronary occlusion (horizontal axis) and total cumulative myocardial release of PBN adducts during the first 10 min of reperfusion (vertical axis) in conscious dogs (group $\mathrm{I}, n=8 ; \bullet)$ and in pentobarbital-anesthetized, open-chest dogs ( $n$ $=11 ; 0)$. Collateral flow is expressed as a percentage of simultaneous nonischemic zone flow; adduct release is expressed in arbitrary units per gram of myocardium (see text for explanation of units). In both groups, there was a negative relationship between release of PBN adducts and collateral flow (the equation for the conscious dogs is indicated in the legend to Fig. 5; the equation for open-chest dogs was: $Y=3437-46.6 X, r=-0.72$ ). For any given level of collateral flow, however, the release of adducts was greater in anesthetized animals.
Plasma and myocardial concentration of $\alpha$-tocopherol. The concentration of $\alpha$-tocopherol was found to be $21.6 \pm 2.7 \mu \mathrm{M}$ (range 14.6-32.9) in the arterial plasma and $0.193 \pm 0.013$ $\mathrm{nmol} / \mathrm{mg}$ of protein (range $0.116-0.249$ ) in the LV myocardium. The concentration of $\alpha$-tocopherol quinone was below detection limits in the arterial plasma and $0.005 \pm 0.0001$ $\mathrm{nmol} / \mathrm{mg}$ of protein in the LV myocardium. None of these values was statistically different from the corresponding values measured in conscious dogs ( see above). Thus, the differences in PBN adduct production (Fig. 7) and wall thickening (Fig. 11 ) between open-chest and awake dogs cannot be ascribed to differences in plasma or myocardial levels of vitamin $E$ or its oxidized form (quinone).

\section{Discussion}

This study demonstrates that, in the conscious, unsedated dog, reperfusion after a brief episode of regional myocardial ischemia is associated with prolonged generation of free radical species. The production of free radicals exhibits a burst in the first few minutes after restoration of flow and then abates, but remains detectable until $1 \mathrm{~h}$ after reflow (and, in some cases, until $3 \mathrm{~h}$ ). No appreciable radical generation occurs after reperfusion when collateral flow during the preceding ischemic episode exceeds $30-40 \%$ of nonischemic flow. In addition, the magnitude of radical generation is directly related to the magnitude of the subsequent depression of contractility. Previous investigations have demonstrated radical production in ischemic/reperfused myocardium in isolated hearts (35-46) or in open-chest animals (1-7, 39, 47). However, to our knowledge, this is the first study to demonstrate production of free radicals

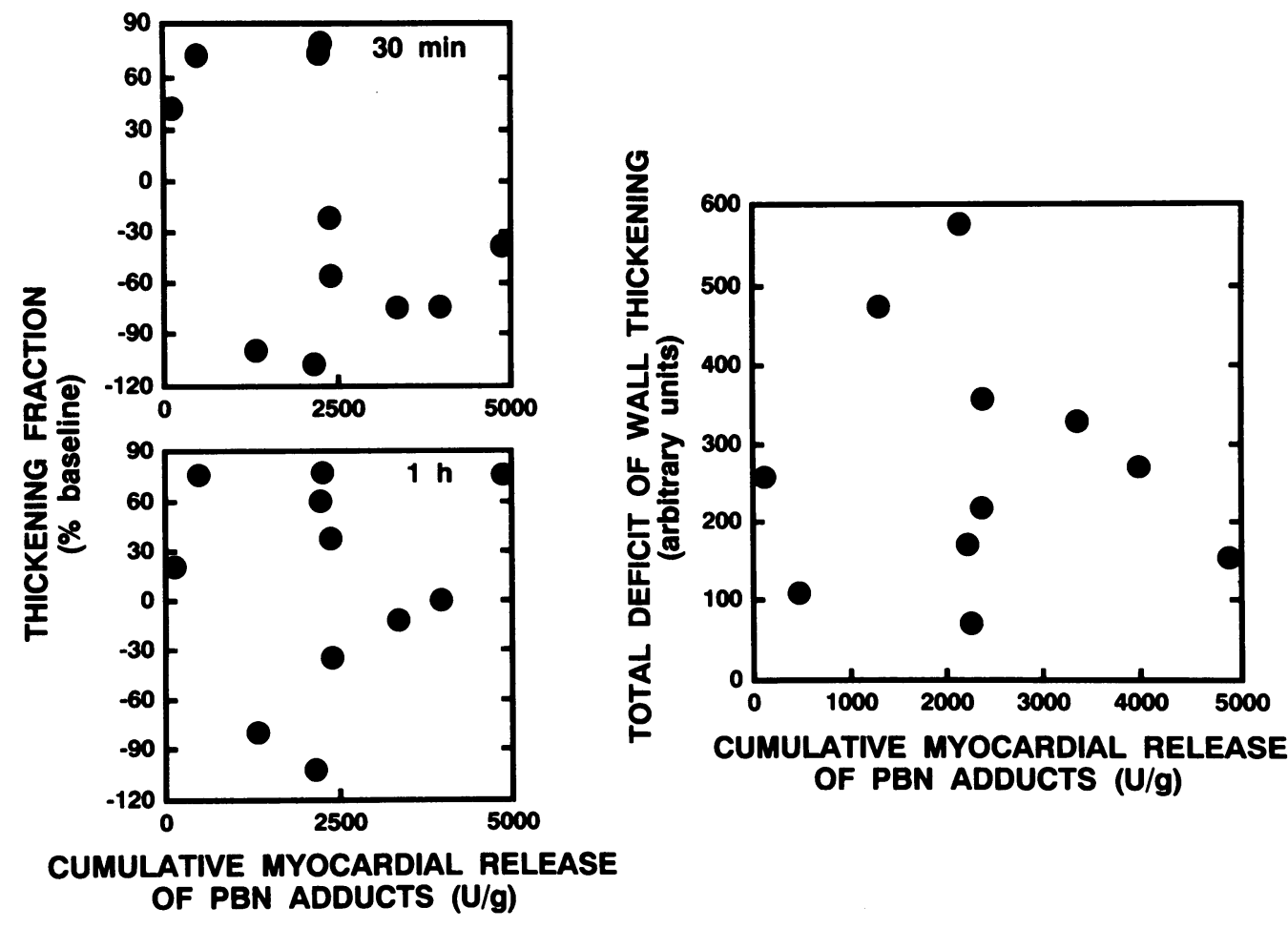

Figure 10. Relationship between total cumulative myocardial release of PBN adducts during the first $10 \mathrm{~min}$ of reperfusion (horizontal axis) and: (a) systolic thickening fraction at $30 \mathrm{~min}$ of reperfusion (left, upper panel), (b) systolic thickening fraction at $1 \mathrm{~h}$ of reperfusion (left, lower panel), (c) total cumulative deficit of wall thickening during the first $3 \mathrm{~h}$ of reperfusion (right panel) (vertical axis) in open-chest dogs $(n=11)$. Adduct release is expressed in arbitrary units per gram of myocardium (see text for explanation of units); thickening fraction is expressed as a percentage of baseline values; deficit of wall thickening is expressed in arbitrary units (see text for explanation). There was no relationship between release of PBN adducts and subsequent thickening fraction or deficit of function. 


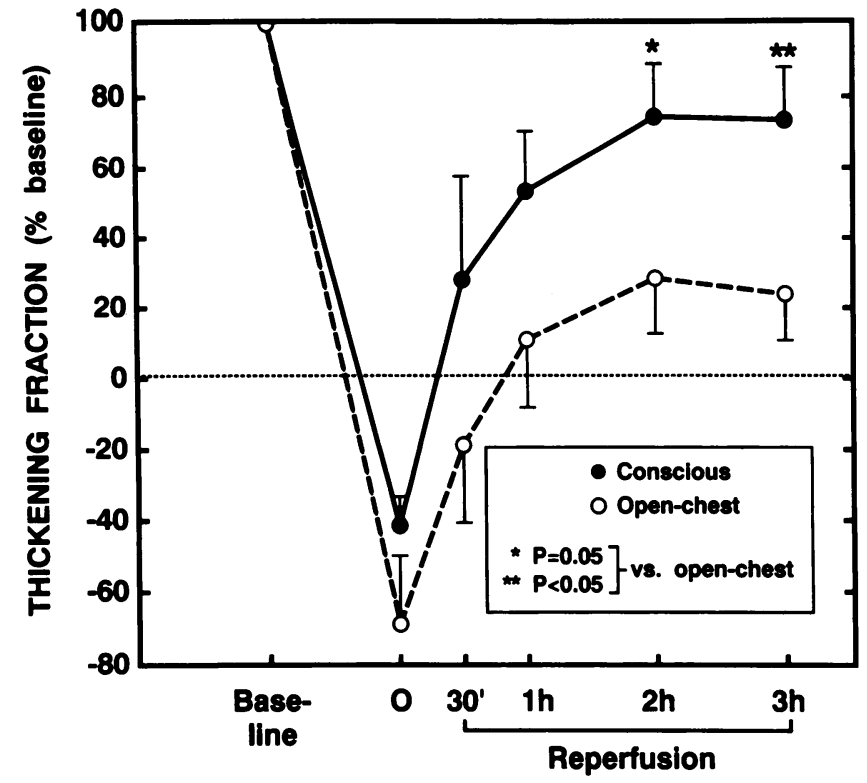

Figure 11. Systolic thickening fraction in the ischemic/reperfused region 5 min after coronary occlusion $(\mathrm{O})$ and at selected times after reperfusion in conscious dogs (group $\mathrm{I}, n=8 ; \bullet$ ) and in pentobarbital-anesthetized, open-chest dogs $(n=11 ; 0)$. Thickening fraction is expressed as a percentage of baseline values. Data are mean+SEM. It should be noted that after reperfusion open-chest animals exhibited active systolic wall thickening (hypokinesis), in contrast to the persistent dyskinesis usually observed in our laboratory $(1,3-5,22,23$, 28 ); this difference is most likely due to the administration of PBN, which has been shown to enhance the postischemic recovery of function in open-chest dogs $(1,3)$.

in postischemic myocardium in conscious animals. The present results significantly expand our understanding of myocardial stunning by suggesting a pathogenetic role of oxygen metabolites which is independent of the abnormal conditions associated with the open-chest animal preparation.

Nature of the PBN adducts in conscious dogs. The precise identity of the radicals trapped by PBN in the conscious dog cannot be ascertained from the present results. Definitive identification of these species will require further complex studies involving adduct isolation and mass spectrometric analysis. From the computer simulation analysis it is clear, however, that at least two different PBN radical adducts (components 1 and 2) contribute to the EPR spectra observed (Fig. 4). These two components are unlikely to be alkoxyl or peroxyl radicals because the PBN adducts of these species usually have $a_{\beta}{ }^{H}$ $<3.0 \mathrm{G}$ in chloroform (29). Since carbon-centered radical adducts of PBN typically have values of $\mathrm{a}_{\beta}{ }^{\mathrm{H}}$ of 3.0-3.5 G (29), the hyperfine coupling constants of component $2\left(\mathrm{a}_{\mathrm{N}}=14.6 \mathrm{G} ; \mathrm{a}_{\beta}{ }^{\mathrm{H}}\right.$ $=3.0 \mathrm{G}$ in chloroform) suggest the trapping of a carbon-centered (alkyl) radical. The identity of component 1 (coupling constants: $\mathrm{a}_{\mathrm{N}}=15.2 \mathrm{G} ; \mathrm{a}_{\beta}{ }^{\mathrm{H}}=6.0 \mathrm{G}$ in chloroform) is more difficult to assign because of the unusually "wide" $a_{\beta}{ }^{\mathbf{H}}$ ( most of the known adducts of $\mathrm{PBN}$ have $\mathrm{a}_{\beta}{ }^{\mathrm{H}}<6.0 \mathrm{G}$ in chloroform). It is possible that this component represents the adduct of a bulky molecule ( such as a phospholipid, which in our experience can give PBN adducts with $\mathrm{a}_{\beta}{ }^{\mathrm{H}}>5.0 \mathrm{G}$ ). The fact that the PBN adducts seen in our study are soluble in nonaqueous solvents and resemble the lipid radical adducts of PBN observed in other systems (29) further supports the notion that they are derived from membrane lipids. In this regard, it is well known that oxyradical-initiated lipid peroxidation gives rise to alkyl radicals (48), which can be trapped by $\mathrm{PBN}$ forming reasonably persistent adducts [29].

These considerations, coupled with the fact that the EPR spectra observed in our dogs are not those of ${ }^{\circ} \mathrm{O}_{2}^{-}$or ${ }^{\circ} \mathrm{OH}$, lead us to conclude that the radicals trapped by $\mathrm{PBN}$ in this study are secondary species, most likely produced during lipid peroxidation reactions initiated by one of the primary oxygen metabolites. This conclusion also explains the fact that the release of spin adducts from the stunned myocardium continued for a relatively long time (at least $1 \mathrm{~h}$ ) after reperfusion (Fig. 3). Although the generation of primary oxyradicals ( such as ${ }^{\circ} \mathrm{O}_{2}^{-}$ and ${ }^{\circ} \mathrm{OH}$ ) may be a relatively brief event, these species could initiate a self-propagating process of lipid peroxidation that could continue in the membrane lipids even after the production of the initiating species has ceased (48), thereby causing a persistent release of PBN adducts. In this regard, a previous investigation ( 1 ) supports the notion that the prolonged release of PBN adducts after reperfusion is due to continued generation of free radicals rather than to slow removal of adducts accumulated during the early phase of reflow.

It is of interest that, in some cases, a large portion of the EPR signals was due to $\alpha$-tocopheroxyl radicals (Figs. 1 and 2 ). $\alpha$-Tocopherol is the major lipid-soluble endogenous antioxidant and is known to react with various radical species forming relatively persistent chromanoxyl radicals (49). The reason for the inconsistent presence of these radicals in the plasma samples is unknown. As noted in the Results, even within the same dog there was an unexplained variability in the release of $\alpha$-tocopheroxyl radicals at different times. In any case, the release of $\alpha$-tocopheroxyl radicals did not appear to affect the release of PBN adducts, since there was no correlation between the two, either in conscious or in open-chest dogs. It should be noted that our method of measuring PBN adducts was not affected by the presence or absence of $\alpha$-tocopheroxyl radicals (see Methods).

Differences between conscious and anesthetized dogs. In the present study the severity of myocardial stunning was more than double in open-chest compared with conscious dogs (Fig. 11), despite the fact that collateral flow, ischemic zone size, PBN plasma levels, and plasma and myocardial $\alpha$-tocopherol levels were similar in the two groups, and that arterial blood gases, hematocrit, and body temperature were within the normal range in all animals. These observations are consonant with a recent study from our laboratory $(21)$ in which the postischemic depression of contractility was found to be approximately twice as great in anesthetized compared with awake dogs. As pointed out in that previous report (21), the mechanism responsible for the large differences in stunning between the two models remains unknown.

In an effort to gain insights into this problem, in the present study we tested the hypothesis that the greater severity of stunning in open-chest dogs may be due to greater generation of free radicals. Our results support this hypothesis. The production of PBN adducts by the stunned myocardium was vastly exaggerated in the open-chest preparation throughout the reperfusion phase, so that the total adduct release noted after $3 \mathrm{~h}$ of reflow in anesthetized animals was approximately five times greater than that observed in conscious animals (Figs. 7 and 8 ). On the basis of these observations, we propose that the level of 
oxidative stress associated with reperfusion is much greater in open-chest vis-à-vis awake animals, and that this difference is responsible, at least in part, for the difference in postischemic depression of contractility.

The reason(s) for the marked disparity in free radical production between anesthetized and conscious dogs remains to be identified. The dosage and modality of administration of PBN, the processing of the blood samples, and the technique for measuring free radicals were identical in the two models. Moreover, the arterial plasma concentration of $\mathrm{PBN}$, the pharmacokinetics of PBN, the plasma and myocardial concentration of $\alpha$-tocopherol and $\alpha$-tocopherol quinone, the magnitude of collateral flow, the size of the occluded/reperfused bed, the postreperfusion flow in the LAD (which is used to calculate PBN adduct production ), and major determinants of myocardial oxygen demands, such as heart rate and systolic arterial pressure, were not significantly different in the two models. Since the EPR spectra were similar to those observed in conscious animals, the greater production of PBN adducts in anesthetized dogs is not likely to be caused by the trapping of different radical species. One possible explanation is that the trauma associated with the open-chest preparation facilitates the release of "free" iron from cellular stores and enzymes, particularly in tissue injured by ischemia and reperfusion. Another possibility is that the excessive adrenergic activity present in barbiturate-anesthetized animals results in increased autoxidation and/or oxidation of catecholamines, thereby promoting excessive generation of free radicals (50).

Whatever its causes, the observed disparity in radical production has important implications for the interpretation of results obtained in anesthetized animals. It is evident from our observations that PBN adduct production in these models consists of two components which overlap and cannot be readily distinguished: a major component (component 1 ), which is model dependent (not present in conscious dogs) and a minor component (component 2), which is model independent (also present in conscious dogs). Since the severity of ischemia, as measured by the collateral flow, was the same in conscious and open-chest dogs (Table IV), it seems reasonable to postulate that component 1 does not really reflect the free radical reactions induced by ischemia per se but instead reflects the peculiar conditions associated with the open-chest model (e.g., anesthesia, trauma, abnormal hemodynamics, etc.). In contrast, component 2 , which is present in both conscious and openchest dogs, appears to reflect the free radical reactions induced by ischemia per se. Unfortunately, since component 1 is much larger than component 2 (by a ratio of $\sim 3: 1$ in the first $10 \mathrm{~min}$ and 5:1 in the first $3 \mathrm{~h}$ of reflow), it could easily confound the assessment of the free radical reactions specifically caused by ischemia/reperfusion (i.e., component 2 ), thereby leading to erroneous conclusions. For example, in open-chest dogs the release of PBN adducts continues at relatively high levels for 3 $h$ (Fig. 7), but since most of this delayed production is not seen in conscious dogs, it cannot be considered a real sequela of ischemia and reperfusion. Furthermore, our observations raise a fundamental question regarding the inhibition of PBN adduct production by antioxidants previously observed in openchest dogs $(3-5,7)$ : does antioxidant therapy inhibit the free radical reactions caused by ischemia/reperfusion per se (i.e., component 2 of PBN adduct production), or does it merely suppress the radical reactions caused by the anesthetized preparation (i.e., component 1 )?

In conclusion, the present study demonstrates large differences between anesthetized and awake animal models. This suggests that concepts derived from acute studies may not be applicable to conscious preparations, and emphasizes the importance of verifying the oxyradical hypothesis in awake animal models.

Correlation between radical production, severity of ischemia, and severity of postischemic dysfunction. In previous investigations $(21,25)$, we found that the magnitude of contractile dysfunction after coronary reperfusion correlates closely with the degree of flow reduction during occlusion $(21,25)$; however, the mechanism responsible for the coupling between reduction of flow and subsequent reduction of function remains unknown. In the present study we postulated that the severity of ischemia governs the severity of stunning by modulating the intensity of free radical reactions. To test this hypothesis, we investigated whether in the conscious $\operatorname{dog}(a)$ radical production after reperfusion correlates with blood flow during ischemia, and $(b)$ radical production after reperfusion correlates with postischemic wall thickening at individual time points or with the total postischemic deficit of function (an integrative measure of the overall severity of stunning). This analysis could not be performed in open-chest animals because in these preparations $(a)$ the severity of myocardial stunning is greatly exaggerated (21), and $(b)$ the animals cannot be followed until function recovers completely, so that the total deficit of function cannot be measured (open-chest animals are usually monitored for 3-4 h after reperfusion, a period which accounts for only a small fraction of their total postischemic dysfunction [25]). In contrast, in our conscious dogs in group I, wall thickening in the LAD region recovered completely by 6 $h$ of reperfusion (Table I), which enabled us to calculate the total deficit of wall thickening. Thus, the use of the conscious dog model afforded an opportunity to correlate radical production with both collateral flow and total postischemic dysfunction.

Using this model, we observed an overall inverse relationship between production of PBN adducts after reperfusion and myocardial blood flow during occlusion (Fig. 5). A more appropriate description of this relationship, however, is that there is a "threshold" of flow during coronary occlusion (corresponding to $\sim 30-40 \%$ of nonischemic flow) above which no appreciable $\mathrm{PBN}$ adduct generation is detectable upon reperfusion, suggesting that a severe ischemic insult (i.e., a flow reduction of at least $60 \%$ ) is necessary to trigger free radical reactions (Fig. 5). Below this threshold, radical production did not correlate significantly with collateral flow (Fig. 5), suggesting that the magnitude of radical formation is influenced by other factors in addition to the level of collateral perfusion. Taken together, these observations demonstrate that the production of free radicals in the stunned myocardium is highly variable, and that the severity of ischemia is a major factor responsible for such variability.

In addition, we observed an inverse relationship between the production of PBN adducts during the initial $10 \mathrm{~min}$ of reflow and the thickening fraction at each of the subsequent time points, and a direct relationship between the production of PBN adducts in the first $10 \mathrm{~min}$ of reperfusion and the total 
deficit of function during the ensuing $6 \mathrm{~h}$ (Fig. 6). The latter regression equation predicts little or no total postischemic dysfunction when PBN adduct production is zero, and a linear increase in dysfunction as adduct production increases (Fig. 6, right panel). The finding that the severity of myocardial stunning during the entire reperfusion phase can be predicted from the magnitude of PBN adduct production during the initial 10 min has important pathophysiological implications: it provides direct evidence supporting the hypothesis that the radicals generated immediately after reflow play a causal role in the subsequent loss of contractility. To our knowledge, this is the first demonstration that postischemic dysfunction correlates with free radical generation in vivo.

In contrast to conscious dogs, in open-chest dogs there was no relationship between production of PBN adducts and severity of myocardial stunning (Fig. 10), probably because both of these variables are profoundly distorted by the anesthetized preparation ( see above). In some dogs, this distortion may involve wall thickening to a greater extent than free radical production, whereas in other dogs the opposite may be true. It is likely that the severity of stunning in open-chest dogs is determined in part by free radicals ("free radical component") and in part by other factors (anesthesia, surgical trauma, manipulations of the heart, lack of integrity of the chest wall, etc.) ("non-free radical component"); if this is the case, then the multiple and complex influences of the variables responsible for the non-free radical component of stunning will confound the relationship between PBN adduct production and postischemic dysfunction. Such relationship may be further confounded by the fact that, as discussed above, the production of free radicals in open-chest dogs appears to consist of two components: a smaller component caused by ischemia (component 2 ), and a larger component caused by factors unrelated to ischemia, such as trauma, adrenergic activity, etc. (component 1), which may vary in a manner independent of, and even directionally opposite to, component 2 . These considerations do not imply that free radicals are unimportant in the anesthetized animal; they simply suggest that the presence of confounding factors makes it difficult to demonstrate a relationship between free radical production and stunning in such models. Thus, the lack of correlation observed in this study is not in contrast with the well-established protective effects of antioxidants in anesthetized models of stunning $(3-5,22-24,28)$. Antioxidant therapy is remarkably effective, resulting in a near-complete suppression of PBN adduct release in open-chest dogs (3-6); it is not difficult to envision how an almost complete elimination of the free radical component of stunning in open-chest dogs can lead to enhanced recovery despite the fact that the nonfree radical component is sufficiently large to confound the relationship between postischemic dysfunction and free radical production.

On the basis of the present results, we propose that the magnitude of flow reduction during occlusion determines whether free radicals are generated in the early phase of reflow, and that the intensity of such generation, in turn, determines the severity of contractile dysfunction during the following hours.

This paradigm has pathophysiological, methodological, and therapeutic implications. From a pathophysiological standpoint, it implies that the mechanisms responsible for the abnormal metabolism of oxygen in the postischemic myocardium are activated by cellular perturbations occurring during ischemia, and that the intensity of such activation is determined by the intensity of flow reduction. In a sense, it appears that the degree of myocardial stunning that will develop after reperfusion is already "predetermined," at least in part, before flow is restored. From a methodological standpoint, studies of antioxidants in models of myocardial stunning should be restricted to animals with low collateral perfusion; furthermore, it is important that collateral perfusion be similar in the various groups of animals being compared. From a therapeutic standpoint, any intervention that improves perfusion during ischemia should attenuate myocardial stunning after reperfusion. Moreover, patients with the most severe ischemia should benefit the most from antioxidant therapy.

Methodological implications. The present results also have methodological implications for the assessment of radical reactions in conscious animals. The major problem associated with these models is to maintain the patency of a selective coronary venous catheter (i.e., a catheter advanced to the mid-LAD level) for the length of time (1-2 wk) necessary to allow full recovery from surgery. The mid-anterior interventricular vein is rather small and its occlusion by the Sones catheter leads invariably to thrombosis, even when the catheter is filled with heparin and is flushed daily. Patency can be easily maintained if the catheter is positioned more proximally (in the great cardiac vein or in the coronary sinus), but blood samples obtained from these locations represent an admixture of venous return from ischemic/reperfused and nonischemic myocardium, which makes it difficult to quantitate radical production. In the present study we have developed a technique (based on continuous infusion of heparin) that permits selective sampling of mid-anterior interventricular venous blood in conscious dogs for a period of weeks, thereby enabling direct measurement of myocardial production of free radicals in the awake state.

By demonstrating the feasibility of applying spin trapping to the conscious animal, our results expand the possible applications of the technique. The approach described herein has the potential not only to demonstrate radical generation, but also to detect relative changes in its intensity on the same day or, if a "chronic" study is being performed, in different days. The use of spin traps in awake animals could, therefore, allow free radical reactions to be assessed over extended periods of time in situations that cannot be modeled in acute experiments. The same basic techniques described in this study can be potentially applied to a variety of organs other than the heart. Spin trapping in conscious animals is admittedly expensive and time-consuming. Nevertheless, in view of the exaggerated free radical production associated with open-chest models (Fig. 7), this approach appears to be necessary before conclusions derived from acute experiments can be extrapolated to humans. With the exception of aromatic hydroxylation techniques ( which measure only ${ }^{\circ} \mathrm{OH}$ ), there is no other established method that can be considered potentially applicable to conscious animal models of myocardial ischemia; thus, for the foreseeable future, spin trapping will likely be the only means of directly assessing production of free radicals other than ${ }^{\circ} \mathrm{OH}$ in these models.

Conclusions. In conclusion, we have demonstrated that free radicals are generated in the stunned myocardium in the ab- 
sence of the artificial or abnormal conditions inherent in previously used models (isolated hearts, open-chest animals). These findings should help remove an important limitation of the oxyradical hypothesis of stunning. Since the production of radicals is dependent on collateral flow and is directly related to postischemic dysfunction, we propose that it may be a crucial mechanism responsible for the coupling between severity of ischemia and severity of stunning. The present study further demonstrates that both the severity of postischemic dysfunction and the magnitude of the attendant free radical generation are greatly exaggerated in open-chest compared with conscious dogs. Because of these striking disparities, previous conclusions derived from anesthetized preparations may not be applicable to awake animals or to humans. Finally, the present investigation provides a method to measure free radicals in conscious animals, and thus should facilitate direct verification of the oxyradical hypothesis in these models.

\section{Acknowledgments}

We thank John I. Thornby, Ph.D., for assistance with statistical analysis, Jennifer S. Pocius and Alex Tumang for excellent technical assistance, and Valerie R. Price for expert secretarial assistance.

This study was supported in part by National Institutes of Health grant HL-43151 and SCOR grant HL-42267 to Dr. Bolli and by the Veterans Affairs Research Advisory Program (Dr. Jeroudi).

\section{References}

1. Bolli, R., B. S. Patel, M. O. Jeroudi, E. K. Lai, and P. B. McCay. 1988. Demonstration of free radical generation in "stunned" myocardium of intact dogs with the use of the spin trap alpha-phenyl $N$-tert-butyl nitrone. J. Clin. Invest. 82:476-485.

2. Leiboff, R. L., C. M. Arroyo, G. L. Schaer, G. W. Mergner, J. H. Kramer, D. L. Miller, M. S. Visner, and W. B. Weglicki. 1988. Free radical generation in an in vivo model of regional myocardial stunning. FASEB J. 2:A818. (Abstr.)

3. Bolli, R., M. O. Jeroudi, B. S. Patel, C. M. DuBose, E. K. Lai, R. Roberts, and P. B. McCay. 1989. Direct evidence that oxygen-derived free radicals contribute to postischemic myocardial dysfunction in the intact dog. Proc. Natl. Acad. Sci. USA. 86:4695-4699.

4. Bolli, R., M. O. Jeroudi, B. S. Patel, O. I. Aruoma, B. Halliwell, E. K. Lai, and P. B. McCay. 1989. Marked reduction of free radical generation and contractile dysfunction by antioxidant therapy begun at the time of reperfusion: evidence that myocardial "stunning" is a manifestation of reperfusion injury. Circ. Res. 65:607-622.

5. Bolli, R., B. S. Patel, M. O. Jeroudi, X. Y. Li, J. F. Triana, E. K. Lai, and P. B. McCay. 1990. Iron-mediated radical reactions upon reperfusion contribute to myocardial "stunning." Am. J. Physiol. 259:H1901-H1911.

6. Bolli, R., and P. B. McCay. 1990. Use of spin traps in intact animals undergoing myocardial ischemia/reperfusion: a new approach to assessing the role of oxygen radicals in myocardial "stunning." Free Radical Res. Commun. 9:169-180.

7. Mergner, G. W., W. B. Weglicki, and J. H. Kramer. 1991. Postischemic free radical production in the venous blood of the regionally ischemic swine heart: effect of deferoxamine. Circulation. 84:2079-2090.

8. Braunwald, E., and R. A. Kloner. 1982. The stunned myocardium: prolonged, postischemic ventricular dysfunction. Circulation. 66:1146-1149.

9. Vatner, S. F., C. B. Higgins, T. Patrick, D. Franklin, and E. Braunwald. 1971. Effects of cardiac depression and of anesthesia on the myocardial action of a cardiac glycoside. J. Clin. Invest. 50:2585-2595.

10. Vatner, S. F., D. Franklin, and E. Braunwald. 1971. Effects of anesthesia and sleep on circulatory response to carotid sinus nerve stimulation. Am. J. Physiol. 220:1249-1255.

11. Cobb, F. R., R. J. Bache, and J. C. Greenfield. 1974. Regional myocardial blood flow in awake dogs. J. Clin. Invest. 53:1618-1625.

12. Vatner, S. F., and E. Braunwald. 1975. Cardiovascular control mechanisms in the conscious state. $N$. Engl. J. Med. 29:970-976.

13. Greisheimer, E. M. 1975. The circulatory effects of anesthetics. Handb. Physiol. (Sect. 2: Circ.) 3:2477-2510.
14. Templeton, G. H., K. Wildenthal, J. T. Willerson, and J. H. Mitchell. 1975. Influence of acute myocardial depression on left ventricular stiffness and its elastic and viscous components. J. Clin. Invest. 56:278-285.

15. Rankin, J. S., P. A. McHale, C. E. Arentzen, D. Ling, J. C. Greenfield, Jr., and $R$. W. Anderson. 1976. The three-dimensional dynamic geometry of the lef ventricle in the conscious dog. Circ. Res. 39:304-313.

16. Manders, W. T., and S. F. Vatner. 1976. Effects of sodium pentobarbital anesthesia on left ventricular function and distribution of cardiac output in dogs, with particular reference to the mechanism for tachycardia. Circ. Res. 39:512517.

17. Jugdutt, B. I. 1985. Different relations between infarct size and occluded bed size in barbiturate-anesthetized versus conscious dogs. J. Am. Coll. Cardiol. 6:1035-1046.

18. Bolli, R., M. L. Myers, W. X. Zhu, and R. Roberts. 1986. Disparity of reperfusion arrhythmias after reversible myocardial ischemia in open chest and conscious dogs. J. Am. Coll. Cardiol. 5:1047-1056.

19. Laxson, D. D., D. C. Homans, X-Z Dai, E. Sublett, and R. J. Bache. 1989. Oxygen consumption and coronary reactivity in postischemic myocardium. Circ. Res. 64:9-20.

20. Ning, X.-H., T. N. Zweng, and K. P. Gallagher. 1990. Ejection- and isovolumic contraction-phase wall thickening in nonischemic myocardium during coronary occlusion. Am. J. Physiol. 258:H490-H499.

21. Triana, J. F., X. Y. Li, U. Jamaluddin, J. I. Thornby, and R. Bolli. 1991. Postischemic myocardial "stunning": Identification of major differences between the open-chest and the conscious dog and evaluation of the oxygen radical hypothesis in the conscious dog. Circ. Res. 69:731-747.

22. Bolli, R., B. S. Patel, W. X. Zhu, P. G. O'Neill, M. L. Charlat, and R. Roberts. 1987. The iron chelator desferrioxamine attenuates postischemic ventricular dysfunction. Am. J. Physiol. 253:H1372-H1380.

23. Charlat, M. L., P. G. O'Neill, J. M. Egan, D. R. Abernethy, L. H. Michael, M. L. Myers, R. Roberts, and R. Bolli. 1987. Evidence for a pathogenetic role of xanthine oxidase in the "stunned" myocardium. Am. J. Physiol. 252:H566H577.

24. Bolli, R., W. X. Zhu, C. J. Hartley, L. H. Michael, J. Repine, M. L. Hess, R. C. Kukreja, and R. Roberts. 1987. Attenuation of dysfunction in the postischemic "stunned" myocardium by dimethylthiourea. Circulation. 76:458-468.

25. Bolli, R., W. X. Zhu, J. I. Thornby, P. G. O'Neill, and R. Roberts. 1988. Time-course and determinants of recovery of function after reversible ischemia in conscious dogs. Am. J. Physiol. 254:H102-H1 14.

26. Charlat, M. L., P. G. O'Neill, C. J. Hartley, R. Roberts, and R. Bolli. 1989. Prolonged abnormalities of left ventricular diastolic wall thinning in the "stunned" myocardium in conscious dogs: time-course and relation to systolic function. J. Am. Coll. Cardiol. 13:185-194.

27. Bolli, R., B. S. Patel, C. J. Hartley, J. I. Thornby, M. O. Jeroudi, and R. Roberts. 1989. Nonuniform transmural recovery of contractile function in the "stunned" myocardium. Am. J. Physiol. 257:H375-H385.

28. Jeroudi, M. O., F. J. Triana, B. S. Patel, and R. Bolli. 1990. Effect of superoxide dismutase and catalase, given separately, on myocardial "stunning." Am. J. Physiol. 259:H889-H901.

29. McCay, P. B., E. K. Lai, J. L. Poyer, C. M. DuBose, and E. G. Janzen. 1984. Oxygen- and carbon-centered free radical formation during carbon tetrachloride metabolism. J. Biol. Chem. 259:2135-2142.

30. Burton, G. W., A. Webb, and K. U. Ingold. 1985. A mild, rapid, and efficient method of lipid extraction for use in determining vitamin $\mathrm{E} /$ lipid ratios. Lipids. 20:29-39.

31. Wallenstein, S., C. L. Zucker, and J. L. Fleiss. 1980. Some statistical methods useful in circulation research. Circ. Res. 47:1-9.

32. SAS Institute. 1988. SAS/STAT User's Guide, Release 6.03 Edition. SAS Institute, Cary, NC. 675-712.

33. Anderson, B. E. 1977. Temperature regulation and environmental physiology. In Duke's Physiology of Domestic Animals. M. J. Swenson, editor. Cornel University Press, Ithaca, NY. 687.

34. Li, X. Y., J. Z. Sun, S. Bradamante, F. Piccinini, and R. Bolli. 1993. Effects of the spin trap $\alpha$-phenyl N-tert-butyl nitrone on myocardial function and flow: a dose-response study in the open-chest dog and in the isolated rat heart. Free Radical Biol. Med. 14:277-285.

35. Zweier, J. L., J. T. Flaherty, and M. L. Weisfeldt. 1987. Direct measurement of free radical generation following reperfusion of ischemic myocardium. Proc. Natl. Acad. Sci. USA. 84:1404-1407.

36. Garlick, P. B., M. J. Davies, D. J. Hearse, and T. F. Slater. 1987. Direct detection of free radicals in the reperfused rat heart using electron spin resonance spectroscopy. Circ. Res. 61:757-760.

37. Kramer, J. H., C. M. Arroyo, B. F. Dickens, and W. B. Weglicki. 1987 Spin-trapping evidence that graded myocardial ischemia alters post-ischemic superoxide production. Free Radical Biol. Med. 3:153-159.

38. Arroyo, C. M., J. H. Kramer, B. F. Dickens, and W. B. Weglicki. 1987 Identification of free radicals in myocardial ischemia/reperfusion by spin trapping with nitrone DMPO. FEBS (Fed. Eur. Biochem. Soc.) Lett. 221:101-104. 
39. Arroyo, C. M., J. H. Kramer, R. H. Leiboff, G. W. Mergner, B. F. Dickens, and W. B. Weglicki. 1987. Spin trapping of oxygen and carbon-centered free radicals in ischemic canine myocardium. Free Radical Biol. Med. 3:313-316.

40. Baker, J. E., C. C. Felix, G. N. Olinger, and B. Kalyanaraman. 1988 Myocardial ischemia and reperfusion: direct evidence for free radical generation by electron spin resonance spectroscopy. Proc. Natl. Acad. Sci. USA. 85:27862789.

41. Zweier, J. L. 1988. Measurement of superoxide-derived free radicals in the reperfused heart. J. Biol. Chem. 263:1353-1357.

42. Zweier, J. L., P. Kuppusamy, R. Williams, B. K. Rayburn, D. Smith, M. L. Weisfeldt, and J. T. Flaherty. 1989. Measurement and characterization of postischemic free radical generation in the isolated perfused heart. J. Biol. Chem. 264:18890-18895.

43. Pietri, S., M. Culcasi, and P. J. Cozzone. 1989. Real-time continuous-flow spin trapping of hydroxyl free radical in the ischemic and post-ischemic myocardium. Eur. J. Biochem. 186:163-173.

44. Baker, J. E., S. Y. H. Tse, and B. Kalyanaraman. 1989. Evidence for hydroxyl radical generation during reperfusion of ischemic myocardium. Circulation. 80(Suppl. II):II-31. (Abstr).
45. Shuter, S. L., M. J. Davies, P. B. Garlick, D. J. Hearse, and T. F. Slater. 1990. Studies on the effects of antioxidants and inhibitors of radical generation on free radical production in the reperfused rat heart using electron spin resonance spectroscopy. Free Radical Res. Commun. 9:223-232.

46. Tosaki, A., and P. Braquet. 1990. DMPO and reperfusion injury: arrhythmia, heart function, electron spin resonance, and nuclear magnetic resonance studies in isolated working guinea pig hearts. Am. Heart J. 120:819-830.

47. Hope, E. J., R. S. Finney, P. Kuppusamy, T. J. Gardner, J. L. Weiss, M. L Weisfeldt, J. T. Flaherty, and J. L. Zweier. 1989. In-vivo measurement of free radical mediated reperfusion injury after hypothermic ischemic arrest. Circulation. 80(Suppl. II):II-295. (Abstr.)

48. Thompson, J. A., and M. L. Hess. 1986. The oxygen free radical system: a fundamental mechanism in the production of myocardial necrosis. Prog. Cardiovasc. Dis. 28:449-462.

49. McCay, P. B. 1985. Vitamin E: interactions with free radicals and ascorbate. Annu. Rev. Nutr. 5:323-340.

50. Jewett, S. L., L. J. Eddy, and P. Hochstein. 1989. Is the autoxidation of catecholamines involved in ischemia-reperfusion injury? Free Radical Biol. Med. $6: 185-188$ 